\title{
¿AUTODETERMINACIÓN O AUTONOMÍA CULTURAL? DEBATES IDEOLÓGICOS EN EL CONGRESO DE NACIONALIDADES EUROPEAS (1925-1939)
}

por

\section{XOSÉ M. NÜÑEZ SEIXAS}

Universidade de Santiago de Compostela.

RESUMEN: Tras el establecimiento de los Tratados de Minorias en la Conferencia de Paz de Versalles (1919) y la articulación de un sistema de protección de las minorias nacionales europeas en el seno de la Sociedad de las Naciones, los representantes politicos e intelectuales de varias minorias de Europa Centro-Oriental convergieron a partir de 1925 en una organización de coordinación de sus iniciativas y que pretendia convertirse en su intermediario ante la Sociedad de las Naciones, el Congreso de Nacionalidades Europeas (CNE). En sus congresos anuales, celebrados hasta 1938, y sus publicaciones e informes, el CNE se convirtió en un foro de discusión acerca de las posibles soluciones de la cuestión de las minorias nacionales en la Europa de entreguerras, y para ello articuló un programa común que bacía bincapié en la necesidad de separar los conceptos de Nación y Estado, y asimismo de diferenciar la esfera de la política de la esfera cultural, a fin de permitir la convivencia de diferentes grupos étnicos dentro de un mismo Estado mediante una aplicación generalizada de la fórmula de la autonomía cultural. La autonomía cultural obedecía a su vez a varias tradiciones de pensamiento politico presentes en Europa Centro-Oriental desde finales del siglo XIX — desde las propuestas de la socialdemocracia austríaca basta las formas de organización corporativa autónoma de las minorias germanas en el Báltico-, pero su plasmación en la Ley de Minorias estonia de 1925 la convirtió en fórmula exportable a otros países. No obstante, dentro del CNE se fueron dibujando con claridad dos modos diferentes de enfocar la cuestión de las minorias, que se personalizan en las propuestas de Paul Schiemann y de Werner Hasselblatt.

Paj,ABras Clave: Historia, Relaciones Internacionales, Siglo XX, Sociedad de Naciones, Nacionalismos, Debate Autodeterminación.

ABSTRACT: With the establishment of the Minoritie. Treaties in the Peace Conference of Versailles (1919), a system of protection of minorities was created witbin the framework of the League of Nations. The political and intellectual representatives of different national minorities all over East-Central Europe merged from 1925 on into a joint organisation to bring their views to the at-

Hispania, LVIII/3, nim 200 (1998) 1113-1151 
tention of the international public opinion, and to attempt to play a mediating role before the League of Nations: this was the Congress of European Nationalities. Through its annual conferences (1925-38) and its reports and publications, the Congress became a discussion forum for all possible theories and models to solve the minorities question. To achieve this end, a common programme was elaborated, which focused on the separation of Nation and State, and also on the differentiation of the cultural sphere from the political one, in order to make it possible for different ethnic groups to coexist within the same state. The solution was to implement a formula of cultural autonomy, which emerged as a combination of different traditions of political thought existing in East-Central Europe from the end of the $19 \mathrm{th}$ century $\rightarrow$ from the models proposed by Austrian socialdemocracy to the corporative autonomy of German minorities in the Baltic area-. But the Cultural Autonomy Lap passed by the Estonian Parliament in 1925 made it the model to be generalised to other countries. Nevertheless, within the Congress two different interpretations emerged about bow to put into practice cultural autonomy, as expressed through the theories of the Baltic Germans Paul Schiemann and Werner Hasselblatt.

KEY wORDS: History, International Relations, 20th Century, League of Nations, Nationalisms, Self-Determination.

Tras la Conferencia de Paz de Versalles (1919), el mapa europeo sufrió una profunda alteración. En Europa Central y Oriental, el hundimiento de los grandes imperios multinacionales dio lugar al nacimiento de nuevos Estados, cuyas fronteras fueron trazadas de acuetdo con las demandas de los movimientos nacionalistas que habían adquirido un gran protagonismo durante la I Guerra Mundial, así como con los intereses geoestratégicos de las potencias vencedoras. El resultado final fue que, si bien fue posible atender las demandas de varios nacionalismos, prácticamente ninguno de los nuevos Estados creados eta homogéneo desde el punto de vista étnico. En todos ellos subsistieron importantes y dispersos islotes de población pertenecientes a un grupo étnico diferente al predominante en su nuevo Estado.

Para compensar las deficiencias de la aplicación del derecho de autodeterminación en los diversos territorios de Europa Centro-Oriental, y en parte también para salvaguardar el espíritu del idealismo wilsoniano que había permitido a la Entente proclamar su causa como la de las pequeñas nacionalidades, así como para evitar que el problema nacional se convirtiese en detonante de una segunda guerra mundial, los vencedores acordaron articular dentro de la naciente Sociedad de las Naciones $(\mathrm{SdN})$ un sistema de protección de minorías situado bajo la garantía de la nueva institución, en cuyo seno funcionó una sección de minorías. Su función habría de ser garantizar que los individuos de raza, lengua o religión diferente a la mayoritaria en un Estado no sufririan dis-

Hispania, LVIII/3, núm. 200 (1998) 1113-1151 
criminaciones en el pleno ejercicio de sus derechos civiles, y gozarían asimismo de unos derechos mínimos en el ámbito de la enseñanza y el culto religioso. El sistema carecía de provisiones que hiciesen posible imponer sanciones a los Estados infractores, y en el procedimiento establecido para la presentación de quejas por parte de las minorías se garantizaba un respeto absoluto al principio de la soberanía estatal, sin que las minorías nacionales fuesen reconocidas nunca como sujetos de derechos colectivos. Pero, con todas sus imperfecciones, representó una primera plasmación internacional e institucional del principio de protección de las minorías a escala continental ${ }^{1}$.

Dentro de esa nueva estructura de oportunidades, los líderes políticos de las minorías nacionales europeas intentaron jugar sus bazas para influir en la SdN y en la opinión pública internacional a fin de que hiciese cumplir los principios de los Tratados de Minorías, defendiese los derechos de las nacionalidades a través del sistema de protección existente, y se consiguiese en última instancia una profundización de los derechos reconocidos a las minorías nacionales. Lo que se concretó en la asunción de las reivindicaciones de las minorías por un amplio abanico de organizaciones internacionales de gran influencia en la opinión pública de algunos países, desde la Unión Interparlamentaria hasta la Unión Internacional de Asociaciones pro-SdN, nacida en 1919. E, igualmente en la aparición de organizaciones internacionales promovidas por las organizaciones políticas de las propias minorías nacionales, con la misión de coordinar sus esfuerzos y elaborar un programa común ${ }^{2}$.

De ellas, la más importante fue el Congreso de Nacionalidades Europeas (CNE), constituido en 1925 a iniciativa de tres grupos de minorias: a) las minorías alemanas en diversos Estados de Europa, particularmente en Letonia, Estonia y Rumanía, así comı los sectores «activistas» - favorables a la participación en las instituciones checas- de la minoría germana de los Sudetes, que habían constituido la Unión de Minorías Alemanas de Europa [Verband der deutschen Minderheiten Europas], con el apoyo crítico de la política exterior alemana, sobre todo desde 1927-28; b) Las minorías judías en diversos países, representadas por el Comité de Delegaciones Judías [Comité des Délégations Juives, CDJ] constituido en París en 1919, con el respaldp de los sionistas norteamericanos; c) varios líderes de minorías eslavas, particularmente de los eslovenos de

1 Sobre el sistema de protección de minorias de la SdN, vid. entre otros Gütermann, C., Das Minderbeitenscbutquerfabren des Völkerbundes, Berlin: Duncker \& Humblot, 1979; THORNBERRY, P., International Law and the Rights of Minorities, Oxford: Clarendon, 1991, 38-52, y MouToN, M.R., «La Société des Nations et la protection des minorités nationales en Europe», Relations Internationates, 75 (1993), 315-28.

2 La bibliografia sobre la cuestión de las minorías en la Europa de entreguerras es inmensa. Para una introducción y contextualización general, puede consultarse nuestro artículo «ational Minorities in East-Central Europe and the Internationalisation of their Rights (1919. 1939)", en J.G. BERAMENDI, R. MÁIz y X.M. NúNEz (eds.), Nationalism in Europe: Past and Present, Santiago de Compostela: USC, 1994, vol. I, 515-45; asimismo, con más detalle, nuestro libro Entre Ginebra y Berlin. La cuestión de las minorias nacionales y la politica internacional en Europa (19141939), Madrid: Akal, 1999 (en prensa). 
Italia y Austria, y d) las minorías magiares en Eslovaquia y Rumanía, muy apoyados por la política revisionista del Gobierno de Budapest. A los promotores se unirían estratégicamente en los años sucesivos otros partidos y líderes de minorías nacionales - desde suecos de Estonia hasta rusos de Moldavia-, entre ellos buena parte del catalanismo político. Tras el primer congreso celebrado en Ginebra en septiembre de 1925, el CNE, contando como presidente al diputado esloveno en Roma Josip Vilfan y como secretario general al político, periodista y activo líder baltoalemán Ewald Ammende (1893-1936), llevó a cabo una importante labor de agitación política y de representación de intereses ante la SdN y ante varias cancillerías europeas. No obstamte, desde 1933 se convirtió progresivamente en un instrumento de la política exterior nacionalsocialista.

Aparte de su labor de propaganda y de "mediación» protodiplomática entre las minorías y la Sd̉N y los diversos Estados europeos, y de sus propuestas para mejorar y ampliar la efectividad del sistema de protección de minorías de la SdN, el CNE sometió a debate en sus congresos anuales las soluciones posibles al problema de las minotías nacionales. Estos debates, en los que se enfrentaron posiciones encontradas desde diversas minorías, constituyen en sí un microcosmos en el que se reflejan las ideas alrededor de la convivencia entre nacionalidad y Estado que circulaban entre los líderes de diversas nacionalidades europeas durante el período de entreguerras ${ }^{3}$.

La situación específica de la mayoría de las minorías nacionales representadas en el CNE requería elaborar una solución que posibilitase la coexistencia en el plano práctico de un sentimiento social de identificación colectiva con la nacionalidad, lo que en la mayoría de los casos implicaba un vínculo de pertenencia con el Estado-madre [Mutterland], y la obligación de guardar fidelidad política al Estado bajo cuya soberanía se encontraban las diversas minorias. Ya que las circunstancias propias de la cuestión de las minorías nacionales en Europa Centro-oriental imponían la necesidad de hallar una fórmula para no alterar el equilibrio entre Estados sobre el que se basaba el sistema de Versalles y preservar al mismo tiempo de los derechos de las nacionalidades esparcidas por varios Estados, las propuestas del movimiento nacionalitario habían de ser por fuerza innovadoras y hasta imaginativas. El objetivo declarado del CNE consistía en intentar resolver la contradicción entre pertenencia a una nacionalidad [Volkszugebörigkeit] y ciudadanía [Staatszugebörigkeit], es decir, encontrar una stercera vías en la que las minorias nacionales podrían coexistir pacíficamente entre sí y con las mayorías étnicas de sus respectivos Estados, manteniendo su lealtad política hacia el Estado pero al mismo tiempo conservando sus derechos culturales y sus vínculos de identidad

3 Las actas de cada congreso anual se publicaron regularmente entre 1925 y 1937 , mayormente en alemán, salvo las del de 1925 (bilingüe francés/alemán) y de 1937, celebrado en Londres (en inglés). Cada informe, publicado en Viena por Braumüller, se titulaba Sitrungsbericht des Kongresses der organisienten nationalen Gruppen Europas, seguido del año de celebración. Para ahorrar espacio, se ha optado por abreviar cada informe con las siglas SB seguidas del año al que se refieren Todas las citas en idiomas extranjeros han sido traducidas por el autor.

Hispania, LVIII/3, núm. 200 (1998) 1113-1151 
colectiva con su grupo nacional allende las fronteras. En este sentido, las propuestas del CNE, aunque basadas en precedentes conocidos e inspirados sobre todo en la experiencia austrohúngara anterior a 1914, constituyeron una elaboración ideológica novedosa y de indudable actualidad ${ }^{4}$.

Elaborar esa tercera vía implicaba ante todo clarificar y separar los conceptos de Nación y Estado, y asimismo establecer qué tipo de relación debía existir entre ambas esferas. Las soluciones avanzadas a nivel teórico por el CNE concedían la prioridad a las soluciones de carácter interno dentro de cada uno de los Estados multinacionales afectados por el problema de las minorías nacionales, antes que a soluciones internacionales, si bien aceptaban el sistema de protección de minorías de la SdN como una solución pragmática y útil en su tiempo, y consideraban deseable su profundización. Pero como ideal político último, el CNE se manifestó inequivocamente favorable a una resolución del problema de las minorías a través de la aplicación general a escala continental de unos principios doctrinales que conducirían por fuerza a la aparición de una nueva Europa basada en la convivencia pacífica entre nacionalidades y Estados no-nacionales, sin alterar las fronteras existentes. Semejante solución implicaba además la renuncia al principio de autodeterminación, aunque buena parte del espíritu wilsoniano permaneció latente en las propuestas del CNE: por ejemplo, su compromiso hondamente democrático con el respeto de las libertades individuales y colectivas.

Sin embargo, los medios prácticos para poner en práctica y posibilitar la aplicación de los principios definidos por los ideólogos del CNE, sintetizados en los debates y resoluciones de sus congresos anuales, nunca fueron definidos con precisión. Se suponía que la creación de un «estado de espíritu» a nivel europeo, de una atmósfera favorable a los derechos de las nacionalidades semejante a la de la Gran Guerra habría de ser un paso preliminar y efectivo para proceder a la generalización de las ideas del movimiento nacionalitatio. A este respecto, las mismas minorías tenían que reproducir y dar vida a la idea original y fundadora de la SdN: a través de la conjunción de los esfuerzos y de la reunión de lo que eran las verdaderas nacionalidades de Europa, se formaria una Sociedad de auténticas naciones, en lugar de la SdN existente, que no era sino una liga de Estados. El hecho de que la actividad del CNE acabase beneficiando en última instancia a los intereses de la diplomacia alemana solamente refleja una cara de la moneda: el fracaso de la puesta en práctica de una estrategia de internacionalización del problema de las minorias nacionales. En un mundo de diplomacia real de Estados, la opinión pública movilizada poseía, por sí misma, limitades oportunidades de éxito, y aún así solamente en algunos países (sobre todo, Gran Bretaña y los Estados Unidos). Por esta razón, el CNE dependió en buena medida de los apoyos externos, fuese

4 En la actualidad de las soluciones, aunque refiriéndose a los antecedentes del $\mathrm{CNE}$, insiste también STOURZH, G., «Problems of conflict resolution in multi-ethnic states: lessons from the Austrian historical experience, 1848-1918n, en U. RaAnAN et al. (eds.), State and Nation in Muli-Ethnic Societies. The Break-Up of Multinational States, Manchester/Nueva York: Manchester UP, 1991, 67-80.

Hispantia, LVIII/3, núm. 200 (1998) 1113-115! 
de los Estados existentes, fuese de las organizaciones que pretendian erigirse en portavoces de la opinión pública.

El CNE fue una organización heterogénea, por lo que dentro de ella cabían varias tendencias ideológicas. El intelectual y teórico baltoalemán de la cuestión de las minorías de tendencia völkisch Max-Hildebert Boehm diferenciaba en 1935 dos sectores dentro del movimiento nacionalitario europeo, si bien se ceñía únicamente a los líderes de las minorías alemans que participaban en él; uno a la derecha, determinado por una posición völkisch-conservadora, y que giraba en torno a la tradición de pensamiento corporativo de los baltoalemanes desde el siglo XIX; y otto a la izquierda, que prefería basarse en las teorías de la socialdemocracia austriaca y en la tradición liberal. Mientras al primer grupo pertenecerían personajes relacionados con los cítculos de la derecha radical alemana próxima a la "revolución conservadora", como H. Ullmann, Stapel, Schmidt-Wodder, Carl von Loesch, Walter Szagunn, el mismo Boehm, Werner Hasselblatt, Bürke, Raschhoffer, Kurt Trampler y Schmidt-Rohr, en el ala izquierda figurarían políticos y juristas en buena parte vinculados al CNE, como Rudolf Laun, J. Tiedje, Paul Schiemann, Wilhelm Medinger, K. Stavenhagen, Otto Junghann, E. Naumann y Camilo Motocutti. Entre ambos sectores, en una posición intermedia o poco definida, se situarian el asesor legal de las minorías alemanas europeas y representante oficioso de las mismas ante el Ministerio alemán de Exteriores, Carl Georg Bruns, o el mismo Ewald Ammende. Un grupo aparte, finalmente, estaría constituido por los líderes católicos de minorias alemanas o Auslandsdeutsche del interior de Alemania, como el surtirolés Reut-Nicolussi, Georg Schreiber o Hugelmann, influidos por las teorías del canciller austríaco Ignaz Seipel y, en algunos casos, por Othmar Spann. Para los partidarios del ala izquierda, el Volk sería en primer lugar una «comunidad de individuos» basada en la voluntad; para los partidarios del ala derecha, el Volk sería ante todo una "sustancia, unidad orgánica»". Las concepciones del ala izquierda, en todo caso, fueron las que más influyeron en el programa oficial del $\mathrm{CNE}$, en conjunción con las aportaciones desde diferentes ángulos de líderes de minorías de otras nacionalidades, fundamentalmente los judíos sionistas y los de nacionalidades occidentales.

Aquí vamos a prestar atención, en primer lugar, al programa general de la organización, tal y como era ratificado en las resoluciones de los congresos anuales y en las publicaciones del movimiento nacionalitario de forma oficial; en segundo lugar, se examinarán brevemente las ideas de dos líderes de minorías baltoalemanes que representan claramente los dos polos en que se fue dividiendo la organización: el del liberalismo nacionalitario, ejemplificado en el máximo ideólogo del CNE, el político alemán y diputado de Letonia Paul Schiemann (1876-1944); y el de la derecha välkisch, representado por el líder alemán de Estonia Werner Hasselblatt (1890-1958).

5 BоEнм, M.H.,Volkstbeorie und Volkstumspolitik der Gegenwart, Berlín: Junker und Dünnhaupt Veriag, 1935, 32-35.

Hispania, LVII/3, núm. 200 (1998) 1113-1151 


\section{EUROPEÍSMO, ANTICOMUNISMO Y PACIFISMO}

El CNE, en primer lugar, era una organización que se proclamaba europeísta. La realización del ideal de unidad europea en el futuro era considerado un requisito necesatio para la solución del problema de las nacionaljdades, y posterior a la consecución de una situación de convivencia ideal en la que Estados y comunidades nacionales pudiesen coexistir en paz. Así, según Schiemann, tras la conciencia de ciudadanía y la nacional vendría un tercer paso: la conciencia europea, «cuando nos sintamos no sólo alemanes, austríacos o letones, sino también al mismo tiempo también todos juntos como europeos, se habrá conseguido mucho para la cohesión de la nación. Cuanto más fácil será la tolerancia cultural mutua, cuando nos digamos que cada iniciativa cultural nacional es al mismo tiempo una participación en la cultura común europeas ${ }^{6}$. Además, según Schiemann, la solución para la cuestión de las minorías nacionales sólo podía ser de alcance europeo, porque implicaba la misma supervivencia del concepto de cultura occidental [abendländliche Kultur], contra un adversatio explícito situado al Este. Como un rasgo constante de las propuestas del movimiento nacionalitario, la idea rival de autodeterminación nacional mantenida por los bolcheviques actuará, en ocasiones de modo más implícito que explícito, como espejo y contraste de las elaboraciones teóricas del CNE. De hecho, las soluciones para el problema nacional ideadas por el CNE se concebían como reacción frente a dos «peligros», rara vez mencionados pero presentes a lo largo de la historia de la organización:

1) La competencia y efectividad de la doctrina de autodeterminación de las nacionalidades elaborada y propagada por la Unión Soviética, cuya influencia era temida por los líderes del CNE. Como alternativa a aquélla, el CNE intentaba elaborar una doctrina que, al tiempo que preservaba las libertades nacionales en toda Europa, mantenía unas fronteras «estratégicas» en Europa Centro-oriental y no implicaba una revisión ulterior de las estructuras sociales y de la distribución de los medios de producción tanto de las mayorías como de las minorías (propiedad de la tierra, etc.). Como expresaba en 1927 el representante de los magiares de Eslovaquia, el terrateniente Geza von Szüllö ?,

«La solución del problema de las minotías es de gran interés para toda Europa. Las reivindicaciones de las minorías nacionales ofrecen sin duda el mejor medio de propaganda para los bolcheviques. Si sus problemas no son resueltos, la desesperación de las minorías nacionales puede llevarlas finalmente al bolchevismos?

El europeísmo del CNE se identificaba así como una unión frente al «enemigo común» soviético ${ }^{8}$. De hecho, en las páginas del órgano oficioso del

6 Schiemann, P., Ein europäisches Problem. Unabbängige Betracbtungen zur Minderbeitenfrage, Viena/Leipzig. Rheinhold Verlag, 1937, p. 41.

7 SB 1927 , p. 89.

8 Wittstock, O., (Die organisierten Volksgruppen und die europäische Idee», Nation und Staat, febrero $1939,289-96$.

Hippania, LVIII/3, núm. 200 (1998) 1113-1151 
movimiento de Nation und Staat serán frecuentes los ataques a la política de nacionalidades de la URSS, considerada como un pretexto para la completa rusificación de todos los grupos étnicos presentes en su territorio. Como argumentaba irónicamente el representante de los rusos de la Moldavia rumana $\mathrm{C}$. von Stanati en 1935, el objetivo final del Gobierno bolchevique, mediante la manipulación de las culturas e idiomas no-rusos, sería conseguir «la fusión de las naciones en una única e igual humanidad proletaria. La supresión de la propiedad privada es considerada como el único e imprescidible medio para disolver las antítesis nacionales. Las particularidades nacionales sólo son contempladas como instrumentos de las burguesías organizadas para el aumento de sus riquezas)" . En verano del mismo año, el órgano oficioso del CNE publicó un número monográfico especial dedicado a la política de nacionalidades soviética, en el que nuevamente se pretendía poner de relieve el rechazo del movimiento nacionalitario a las soluciones ideadas por los bolcheviques, que, pese a su apariencia «favorable a los pueblos» era reducida a kun disfraz de la fija determinación de asestar a cada nacionalidad el golpe de muerte. Lo que se refiere tanto al chauvinismo gran-ruso como a los localess ${ }^{10}$. Del mismo modo, Ammende llevó a cabo desde 1932 una amplia campaña de propaganda contra el hambre en la URSS por varios países, aunque en realidad estaba orientada a combatir el ingreso de la Unión Soviética en la SdN, desprestigiándola internacionalmente y, de paso, desviando la atención de la opinión pública de la Alemania nazi. Sin embargo, hasta los líderes sionistas, como el judío-checo Emil Margulies, manifestaban en 1934 su enemiga al comunismo soviético, considerado un «peligro") para el pueblo judío: «Nada amenaza tanto la construcción de nuestro Estado en Palestina como el reforzamiento del movimiento comunista en nuestras filas. Nada amenaza tanto nuestra posición en el mundo como el compromiso con la literatura del libertinaje judío-comunistay) ${ }^{11}$.

No obstante, la política de nacionalidades soviética aparecía ante el exterior como un modelo de tolerancia y respeto hacia las culturas minoritarias. Por ello, en sus propuestas de trabajo para el X Congreso de Nacionalidades de 1934 Ammende señalaba como punto importante la denuncia de la política soviética de nacionalidades, con el argumento de que sólo se reconocían los idiomas y culturas nacionales si los ciudadanos de esos pueblos no-rusos estaban dispuestos a servir al comunismo, y se acompañaría del «terror comunista contra las minorias y sus integrantes, como los alemanes, polacos, checos, etc.n. Para ello, sugetía dar mayor protagonismo a los nacionalistas ucranios dentro del $\mathrm{CNE}$, con el fin de que destruyesen «la falsa imagen de la Rusia soviética como un paraíso para las minorias» ${ }^{12}$.

\footnotetext{
9 von Stanati, C., “Zut Nationalitätenpolitik der Sowjetunion», Nation und Staat, eneto 1935, 224-27.

10 vON UEXKOLL, F, «Die bolschewistische Lösung des Nationalitätenproblems», Nation und Staat, julio/agosto 1935, 634-59.

11 Margulies a Vilfan, Leitmeritz, 1.1.1934 (BB]undesarchiv [K]oblenz-[A]rchivo Josip [V]ilfan).

12 AmmEnde, E., Aktuelle Aufgaben und Arbeiten der Europäischen Nationalitäten-Kongresse, s.f. (1934), BK-AV.
}

Hiparnia, LVIII/3, nưm. 200 (1998) 1113-1151 
Pero las propuestas del CNE no estaban interesadas y condicionadas únicamente por la necesidad de oponerse al avance del socialismo por Europa desde la URSS. El impacto de la revolución soviética, y la posible influencia directa de la Komintern sobre el desarrollo de la cuestión nacional en Europa Centro-oriental, había disminuido mucho en intensidad en la segunda mitad de los años 20, si bien había sido determinante en la adopción por el Gobierno estonio de la Ley de Autonomía Cultural en 1925. Eso sí, no se trataba tanto del temor directo a que el descontento de las minorías pudiese ser instrumentalizado por los partidos comunistas, como de la cierta difusión y la imagen exterior que había alcanzado la URSS como modelo de resolución política interna de la cuestión nacional en um modo aparentemente igualitario que permitía incluso a las diversas nacionalidades integrantes ejercer el derecho de autodeterminación, llegando así a una federación "voluntaria» en el Estado soviético. Esa imagen habia tenido una acogida ciertamente favorable entre numerosos movimientos nacionalistas y círculos dirigentes de las minorías nacionales europeas, sin ir más lejos dentro del nacionalismo catalán ${ }^{13}$.

2) Por otro lado, la compleja situación de las nacionalidades y minorías existente en Europa Centro-oriental implicaba una falta permanente de equilibrio político entre las mayorías y minorías étnicas dentro de un mismo Estado. Dado que las mayorias siempre elegían un número proporcionalmente mayor de representantes parlamentarios en relación a los que podín ser elegidos por las minorias, la supervivencia de la misma democracia parlamentaria en esa parte de Europa estaba amenazada directamente por la cuestión de las minorías nacionales: éstas acabarían por negar la legitimidad política a un sisterna que perpetuaba su inferioridad de condiciones y su marginación de las mayorías legislativas y de gobierno. En consecuencia, el sistema democrático proporcional podría ser incluso puesto en tela de juicio por los movimientos nacionalistas que aspiraban a la defensa de los derechos de las minorías, ya que la «vía legab» parecía estar bloqueada. La contradicción, de todos modos, no fue permanente, ni tampoco se producía con la misma intensidad en todos los casos, como demuestra el ejemplo de los partidos alemanes activistas de los Sudetes durante los años $20 \mathrm{y}$ parte de los 30 , basados en el fuerte peso demográfico de la minoría germana en el conjunta de Checoslovaquia. Peto en la mayoría de los Estados parecía necesario arbitrar una solución pactada o consociacional más amplia para garantizar a largo plazo la convivencia de minorías nacionales y mayorías dominantes, o, si se quiere, de nacionalidades dispersas y

13 Por ejemplo, el lider de la Lliga Joan Estelrich exa capaz en 1929 de expresar su preferencia por una combinación de solución federal para las nacionalidades según el modelo soviético y de corporativismo social según el modelo de la Italia fascista (EsTeIrich, J. E., La qüestió de les minories nacionals $i$ les rites del Dret, Barcelona: Catalònia, 1929). Sobre la participación catalanista en el CNE, vid. nuestro articulo «Il nazionalismo tátalano e la diplomazia spagnola di fronte al sistema di protezione delle minoranze nazionali della Società delle Nazioni (19191930)», Storia delle Relazioni Internazionali, VI:2 (1993), 3-65.

Hispania, LVIII/3, núm. 200 (1998) 1113-1151 
Estados sobrepuestos a las fronteras étnicas ${ }^{14}$. A pesar del hecho de que los "Estados sucesores» estaban sujetos a las obligaciones de los Tratados de Minorias, y de que los líderes nacionalistas que después serían jefes de Gobierno habían prodigado durante la Gran Guerra garantías de que las minorías étnicas serian objeto de una especial legislación protectora de sus derechos culturales, los años sucesivos mostraron una realidad muy diferente.

En opinión del CNE, todos estos hechos solamente mostraban la medida en que un principio real de tolerancia nacional estaba ausente de la política europea del momento, y era sustituido por una intolerancia general hacia los derechos nacionales de otros pueblos. Por esta razón, la evolución de la cuestión de las minorías en los Estados bálticos fue seguida por los líderes de las minorias europeas con gran atención: en concreto, la Ley de Autonomía Cultural de Estonia (1925) se convirtió en un auténtico modelo a imitar y perfeccionar para conseguir mejores resultados. La combinación de disposición propia para gobernar sus asuntos culturales y educacionales en manos de las minorías, junto con la ausencia de implicación política en la aplicación y consecuencias de la ley, al basarse en el principio de adscripción individual a la nacionalidad ( $\mathrm{y}$ no en un principio de dependencia territorial), fueron factores que contribuyeron a la difusión del modelo estonio. De hecho, semejantes principios a los expresados en la ley estonia y, en menor medida, letona (de autonomía escolar), cuyos promotores habían sido algunos de los líderes del $\mathrm{CNE}$, fueron inmediatamente exteriorizados y preconizados por el movimiento nacionalitario. En las resoluciones del primer Congreso de $\mathrm{Na}$ cionaliades Europeas (1925), figuraba que el derecho a la libertad nacional y cultural constituía una reivindicación primaria de todas las minorías nacionales, que habría de ser aplicada a las relaciones entre mayorías y minorías, así como una suerte de principio ético (no político), que habría de ser garantiado por las leyes del futuro:

«En relación con ello, cada Estado en cuyas fronteras viven también otros grupos nacionales debe garantizar a aquéllas como comunidades el pleno desartrollo cultural y económico, y a sus integrantes el disfrute libre y sin restricciones de sus derechos ciudadanos., ${ }^{15}$.

La misma reivindicación se manifestaba en las conferencias posteriores del CNE: es decir, la obligación de la comunidad internacional y de cada Estado en particular de reconocer la libertad de todas las minorías nacionales para desarrollar sus actividades y derechos culturales. El V Congreso del CNE (1929) proclamaba igualmente que «la garantía de los derechos culturales nacionales y

14 Vid. ViefHaus, E., «Nationale Autonomie und patlamentarische Demokratie», en W. KiUXEN Y W.J. MOMMSEN (eds.), Politische Ideologien und nationalstatliche Ordnung, Munich/Viena: Oldenbourg, 1968, 377-92.

$15 \mathrm{SB} 1925$, p. 70,11 resolución.

Hipania, LVIII/3, núm. 200 (1998) 1113-1151 
de los derechos ciudadanos de las minorias nacionales debe convertirse en un principio vinculante de la ley europea», lo que continuó de modo invatiable hasta el XIV. Congreso celebrado en Estocolmo (1938) ${ }^{16}$.

El principio de tolerancia nacional, cuyo fin último era el cuidado y conservación las características culturales y étnicas de cada una de las minorías por parte de sus propios integrantes, tambiến se suponía como un "principio ético", fundamento del Derecho, "principios éticos fundamentales, que constituyen la base del mundo cultural europeos ${ }^{17}$. El derecho al desarrollo de la personalidad nacional de cada minoría étrica era considerado como un derecho natural, fundado incluso en la voluntad divina según algunos de los líderes del CNE. Pero, igualmente, el libre desarrollo del Volkstum no entraba en contradicción con la conservación de los Estados, incluso de los Estados multinacionales, como forma política que poseía una naturaleza diferente de la nación. En consecuencia, si ambos elementos - nación y Estado- lograban coexistir $\mathrm{y}$ trabajar conjuntamente en la vida cotidiana y en la construcción del bienestar, respetándose mutuamente, las causas de tensión nacional en Europa acabatían por desaparecer. Como señalaba Ammende en la primera conferencia del $\mathrm{CNE}$, la misión de la organización consistiría precisamente en establecer unos principios ideológicos y políticos que pudiesen satisfacer a mayorías y minorias étnicas: los postulados del CNE serían «un programa cuya realización va en interés no sólo de las nacionalidades, sino también de las mayorias étnicas y hasta de los Estados. Sólo partiendo de este programa, que apela no sólo a la moral, sino al mismo tiempo a los intereses vitales y existenciales de los Estados, tendremos la posibilidad de apartar los recelos y crear vínculos que hagan posibles la comprensión mutua, y con ello la consecución de nuestro fins 18 .

Un argumento añadido, y utilizado profusamente tanto por los líderes del CNE como por los pacifistas, era el peligro que entrañaba la persistencia de la «intolerancia nacionals para el mantenimiento de la paz europea, para lo que se invocaba el recuerdo de la I Guerra Mundial. Las luchas internas entre minorías y mayorías étnicas dentro de un Estado podrían implicar la intromisión en el conflicto del Estado connacional de la minoría afectada. En este caso, el peligro de que el malestar de las minorías nacionales provocase un nuevo conflicto bélico devenía una probabilidad real ${ }^{19}$. Este argumento poseía gran eficacia propagandística, ya que podía causar impacto entre la opinión pública

16 SB 1929, p. 141, 11 resolución; Nation und Staat, vol. 11 (1937/38), p. 731, 11 resolución.

17 Intervención del Dr. Margulies, en SB 1928, p. 60.

18 Intervención de Ammende, SB 1925, 67-68.

19 Vid. VIlfan, I, «Das Europäische Nationalitätenproblem und das Problem des Friedens», Nation und Staat, mayo 1936; igualmente, en su obra Les minorités ethriques et la paix (Viena: Braumülier, 1929) apunta en las conclusiones (14-15) que la SdN acabaría por darse cuenta del problema planteado por la espiral asimilación esłatal/rebelión de las minorías/represión nacional, y que, con la ayuda de las organizaciones intemacionales, acabaria por tomar cartas en el asunto. En semejantes argurnentos insistia por ejemplo BRUNs, C.G., (Die nationalen Minderheiten in Europa als intenationales Problems, en id., Gesammelte Schriften zur Minderheitenfrage, Berlín: Heymanns Verlag, 1933, 11-21.

Hispania, LVIII/3, núm. 200 (1998) 1113-1151 
europea y concitar apoyos externos a la causa del movimiento nacionalitario. Así se reveló, por ejemplo, en el compromiso personal de personajes relevantes de la política británica como Lord W. Dickinson o Robert Cecil, para quienes, sin embargo, la protección de grupos étnicos o minorías nacionales constituía ante todo una consecuencia del principio más general de respeto de los derechos humanos, y no del reconocimiento de derechos a colectivos ${ }^{20}$.

El CNE ponía particular esmero en resaltar, siempre que era posible, que su único objetivo era promover el entendimiento universal entre los pueblos de Europa. Asegurando esta condición, la paz del continente podría ser preservarse, evitándose el peligro de una nueva guerra mundial. Como Vilfan resaltaba en 1927, «Europa necesita la paz, y sólo encontrará una paz duradera y construida sobre la humanidad y no sobre la violencia cuando los derechos de las nacionaliades, el artículo fundamental de la comunidad europea de los pueblos, serán finalmente reconocidos y puestos en prácticas ${ }^{21}$. Y en $1939 \mathrm{el}$ presidente del CNE todavía seguía considerando que la única solución para el problema de las nacionalidades en Europa pasaba por la internacionalización de un «Derecho de Nacionalidades", rechazando los acuerdos bilaterales entre Estados para la protección de sus respectivas minorías connacionales, pues con esta última solución aquellas nacionalidades que careciesen de un fuerte Estado protector estarían en desventaja:

«No creo en el principio etnográfico como el único criterio, ni siquiera el más importante, para la delimitación de las fronteras estatales. Por eso, creo en la inevitabilidad y, por diversas razones, en la necesidad de la existencia de diferentes nacionalidades dentro de cada uno de los Estados nacionales. Y, finalmente, creo también en la necesidad de que todos los Estados europeos abandonen la vía de la homogeneización, más tarde o más temprano, que se establezca la estructura étnica del continente mediante un derecho de nacionalidades europeo que lo libere del odio nacional.» 22 .

\section{NACIÓN, NACIONALIDAD Y ESTADO}

La defensa de los principios expuestos llevaba también al rechazo del principio de autodeterminación, a pesar de no ser nunca explícitamente negado por el CNE en razón de su heterogeneidad interna y porque en la organización participaban representantes del nacionalismo catalán, vasco o ucranio, que no se mostraban dispuestos a renunciar a él. Ahora bien, si el CNE mantenía como ideal el construir una nueva teoría de la nación, basada sobre la perservación de las fronteras y Estados existentes tras 1919 y la despolitización de las reivindicaciones nacionales, su oposición al principio de las nacionalidades y al derecho de autodeterminación era más que implícita, ya que se negaba la virtualidad

\footnotetext{
20 Vid. CECIL, R, Minorities and Peace, Londres: Jewish Historical Society, 1934.

21 Intervención de Vilfan, en SB 1927, pág. 16.

22 Vilfan a Th. Ruyssen, Viena, 11.1.1939 (BK-AV).
}

IHspanta, LVIII/3, núm. 200 (1998) 1113-1151 
de la fórmula del Estado nacional, y por lo tanto que a cada nacionalidad le tuviese que corresponder un Estado. La oposición al Estado nacional estaba firmemente representada, sobre todo, por la tendencia «izquierdista» encabezada por Schiemann, quien veía en el principio de autodeterminación una amenaza para la paz europea, en cuanto llevaba a los Estados a «homogeneizab» étnicamente a su población ${ }^{23}$. La formación de Estados nacionales era incompatible con el poblamiento étnico mixto y disperso de Europa Centro-oriental, aunque no se rechazaba por principios teóricos, como Schiemann exponía ya en la primera conferencia del CNE en 1925: la aplicación del principio de autodeterminación era incapaz de resolver todos los problemas nacionales, en cuanto «siempre permanecen en los Estados nacionales grupos de población más grandes o más pequeños que pertenecen a otra nacionalidad, y que tienen la necesidad de su desarrollo culturabs ${ }^{24}$. Por el contrario, para la mayoría de las nacionalidades representadas en el CNE, y según la postura oficial de la organización, la solución de la cuestión de las minorias no residía en la alteración de las fronteras estatales conforme a imposibles líneas de demarcación étnica, sino que dependería mucho más de la posibilidad de relativizar la importancia real de las fronteras. La oposición entre fronteras étnicas y estatales habría de desaparecer en la misma medida en que lo haría la oposición entre ciudadanía y nacionalidad. El medio para superar esa oposición sería llevar a la práctica y dotar de contenido a una concepción supranacional de comunidad estatal [Staatsgemeinscbaff], diferenciándola nítidamente de la idea de comunidad etnonacional-cultural [Volksgemeinschaft] ${ }^{25}$. Los Estados deberían resignarse a ser multinacionales, sin que existiese monopolio alguno del poder del Estado por parte de un grupo étnico sobre los demás; en contrapartida, el Estado debía proteger y garantizar el libre desarrollo de la vida cultural de las diferentes nacionalidades incluidas dentro de sus fronteras. Cada uno de los grupos étnicos había de disponer de un espacio propio encarnado en sus instituciones y asociaciones culturales, corporativas o profesionales, siendo el resultado final que "cada nacionalidad configura un propio espacio vital [Lebensraum], siendo todos protegidos por el Estadon ${ }^{26}$. En este sentido, el baltoalemán Werner Hasselblatt se hacía eco en 1930 de la necesidad de arribar a una suerte de «Código legal» para las minotías, que habría de garantizar precisamente la supervivencia cultural de cada una de ellas dentro de un mismo Estado ${ }^{27}$.

\footnotetext{
23 Discurso de Schiemann, en SB 1925, pág. 18.

24 SCHIEMANN, P., «Nationalitätenprobleme», Europäische Revue, IV (1928), 460-71.

25 Evidentemente, el concepto de Volksgemeinschaft tiene una larga historia dentro del pensamiento reaccionatio alemán, pero asimismo reviste una gran polisemia. Su uso fue generalizado entre diferentes sectores ideológicos tras 1919, y no sólo por la derecha nacionalista de inspiración autoritaria (ivilkiscb).

26 W. Hasselblatt, en Nation und Staat, vol. $3(1929 / 30), 570-75$.

27 HASSELBLAT, W., (Auf dem Wege zu einem Minoritätenkodex», Nation und Staat, 10-11 (1930), pág 1040.
} 
En función de ello, los integrantes de una minoría nacional no deberian enfrentarse a ningún dilema al asegurar su lealtad como ciudadanos al Estado al que perteneciesen: una vez que el Estado concediese una libertad cultural a las minorias, éstas debían colaborar fielmente con las mayorías y demás grupos étnicos existentes en ese Estado en las tareas de Gobierno, economía y administración. Según como expresaba el pastor protestante y líder de la minoría alemana en Schleswig septentrional, J. Schmidt-Wodder, en 1926: «Los grupos étnicos están dispuestos a dar al Estado lo que es del Estado, cuando los Estados estén dispuestos a dar a los grupos étnicos la garantía de su existencia y a no interferir en su fidelidad a su nacionalidad» ${ }^{28}$. Como posible intermediario entre la fidelidad a la nación y al Estado se apelaba en ocasiones a la potenciación del amor a la patria local [Heimat] o espacio geográfico habitado por las minorías, como posible amortiguador de tensiones, siguiendo el ejemplo de los baltoalemanes 29 .

El CNE situaba al Estado, por lo tanto, en un plano diferente al de la Nación, y rechazaba que el fin del desarrollo de una nacionalidad fuese el constituir un Estado propio y homogéneo. El Estado era una mera realidad jurídico-institucional, si bien en los discursos de varios de los líderes participantes en el CNE - tanto representantes de nacionalismos occidentales como de algunos orientales, y aún en los años 30 por parte de delegados de los alemanes de los Sudetes - se siguiese considerando al Estado como la expresión final más completa del desarrollo de la nación. Pero no era el único instrumento ${ }^{30}$. Por el contrario, el Estado sería meramente un espacio en el que diferentes nacionalidades podrían coexistir y compartir funciones políticas, así como desarrollar su libertad cultural, consiguiendo un sentimiento de solidaridad «fraternabs entre ellas ${ }^{31}$. Esa concepción llevaba a una valoración diferente del término nacionalismo, entendido como reivindicación política del autogobierno territorial de una nacionalidad determinada. Los líderes del CNE se hacían eco de un concepto alternativo y hasta shumanista» de nacionalismo: el judío Leo Motzkin afirmaba que «el nacionalismo [...] sólo es un verdadero nacionalismo, cuando tiene una comprensión no sólo por su nación, sino al mismo tiempo por las demás naciones» ${ }^{32}$. El CNE, al menos en el plano teórico, creía en un nacionalismo solidario y al mismo tiempo meramente defensivo, que tuviese el único fin de preservar los signos de identidad cultural y las formas de vida tradicionales y distintivas de una comunidad étnica. En este

\footnotetext{
28 SB 1926, pág. 35.

29 VON UEXKÜL_GÜLDENBAND, F, «Der Heimatbegriff der Volksgruppen», Nation und Staat, noviembre/diciembre 1936.

30 Vid. por ejemplo el discurso del delegado de los alemanes de los Sudetes H.O. Roth, en SB 1932, pág. 51: «os dirigimos contra la equiparación formal de nación y Estado. Sinuamos a la nación en primer lugat, y el Estado sólo es una de las formas, si bien la más fuerte y efectiva, de la nación'.

31 Intervención de G. von Szüllö, en SB 1934, pág. 29.

32 Discurso de Leo Motzkin, en SB 1926, pág. 32.

Hispania, LVIII/3, nưm. 200 (1998) 1113-1151
} 
sentido, afirmaba diferenciarse del nacionalismo de Estado, así como del nacionalismo agresivo. El nuevo nacionalismo solidario tendría la función de contribuir a una comprensión mutua entre todos los pueblos de Europa, y especialmente de las minorías nacionales, que podría servir a su vez de mediadores o puentes de concordia entre varios Estados; y, al mismo tiempo, como expresaba Schiemann en 1937, había de ser corresponsable con otros nacionalismos o minorías nacionales de las tareas políticas del Estado ${ }^{33}$.

La coexistencia entre diferentes pueblos sólo era posible por la fe en un nuevo orden supranacional europeo, en el que las diferentes naciones habrian de convivir en paz y armonía, idea que se remontaba ya a Herder. Al igual que en la concepción herderiana, la variedad y diversidad natural de culturas y nacionalidades era considerada un hecho positivo en sí, que contribuía a forjar una cultura plural de la Humanidad y a la consecución de una forma indefinida de armonía mundial superior. La cultura y civilización europeas se mantendrían gracias a la coexistencia de diferentes culturas nacionales, de varias Volksgemeinschaften interactivas, con el orden de Estados y fronteras existente, a pesar de ser los segundos construcciones arbitrarias y antinaturales. El CNE resumió este postulado en 1930:

eLa cultura de Europa es en su sentido más profundo la exteriorización de la vida espiritual de las diferentes naciones europeas como comunidades particulares [...]. La cultura europea debe en primer lugar su riqueza y su constante renovación a la variedad de esas comunidades nacionales, su mutua y cambiante interinfluencia, la confrontación y equilibrio entre los modos de ser particulares de los pueblos y entre cada uno de ellos y el patrimonio cultural común de la humanidad europea,» ${ }^{34}$.

El concepto de nación abrigado por el CNE era deudor de la concepción herderiana de Volksgemeinschaft, basada a su vez en el concepto de Volkstum, y se definía por la posesión de una lengua común, costumbres, experiencia de vida colectiva y cultura. Como afirmaban las resoluciones del Congreso anual de la Unión de Minorías Alemanas de 1934 (Danzig), el Volkstum sería «más que una comunidad de idioma. Es además una comunidad de sangre, de espíritu y de vivencia, una comunidad que no puede ser abolidas ${ }^{35}$. El idioma era considerado, en primer lugar, el factor clave en la formación de la nacionalidad, especialmente para las minorias nacionales dispersas por varios Estados ${ }^{36}$. Aunque

33 SCHIEmann, P., en Volksdeutscher Presse- und Informationsdienst, 15.6 .1937 (citado por Kemes, E., Europässcher Nationalitätenkongreß 1925-1938, tesis doctoral, Universidad de Colonia, 1956, pág. 162).

34 «Resolution zur Organisation der Volksgemeinschaften», en SB 1930, pág. 146. Vid también NeugEBoren, E. «Die überstaatliche Volksgemeinschaft), Nation und Staat, noviembre 1935.

35 «Danziger Tagung des Verbandes der deutschen Volksgruppen in Europa», Nation und Staat, abril 1934.

36 J. GrünBaum, en SB 1927, pág. 128.

Hípania, LVII/3, núm 200 (1998) 1113-1151 
las definiciones teóricas excluían, en principio, cualquier referencia a la conciencia individual y a la voluntariedad de pertenencia de los integrantes de una nación[alidad], en la formulación de la solución práctica de la autonomía cultural, como veremos, sí se introducía un elemento de voluntariedad: sería miembro de una nacionalidad aquel indivuduo que quisiese inscribirse previamente en un censo como integrante de la misma.

Dado que las naciones habian de coexistit con Estados multinacionales, debía definirse una precisa división de esferas y funciones entre Nación y Estado. En primer lugar, las naciones orgánicas habrían de ser reconocidas jurídicamente como sujetos del Derecho Internacional, acabando con la filosofía liberal-individualista de los Tratados de Minorías. El Estado debía renunciar a varias de sus competencias para permitir a las nacionalidades el desarrollo de su «espacio vital». Las nacionalidades debían renunciar a toda reivindicación de control específico sobre cuestiones políticas, jurídicas o económicas. Ahora bien, el Estado debía garantizar a las minorías nacionales condiciones plenas y suficientes para su supervivencia económica, asegurando la igualdad de oportunidades en ese campo entre minorias y mayorías. El CNE, en este aspecto, nunca reivindicó competencias económico-financieras para las instituciones autónomas de las minorías, aparte del objetivo de plena igualdad ante la ley para todos los ciudadanos de un Estado en lo referente a sus posibilidades y opciones en el campo económico. Otra condición a ser garantizada por el Estado a las minorias nacionales era la protección y disfrute de derechos civiles sin restricción alguna ${ }^{37}$. Ambas garantías (derechos civiles e igualdad de oportunidades económicas) constituian elementos previos para el libre desarrollo de las características nacionales de cada uno de los grupos étnicos, a través de la consolidación de sus respectivas Volksgemeinschaften, que se ceñirían al ambito cultural, setían suprapartidarias y supraconfesionales, independientes de los factores políticos coyunturales y tolerantes hacia la diversidad ${ }^{38}$.

La delimitación de esferas de competencia entre el Estado y las nacionalidades sería fijada, en primer lugar, a través de una suerte de Derecho de $\mathrm{Na}$ cionalidades interno en cada Estado, basado en el acuerdo entre mayorías y minorías. Esta vía era considerada como una solución ideal frente al sistema de protección de minorías, y consistiría en un proceso de negociación entre el Estado y las minorías nacionales que crease una atmósfera de concordia y confianza. El CNE proponía la creación de «Comités de Arbitraje» integrados por representantes tanto de las mayorias como de las minorías étnicas, bajo el control de la Unión Interparlamentaria, para mediar en todo posible conflicto nacional interno. La SdN era considerada, en este contexto, como la última institución a la que sería posible apelar en el caso de que el procedimiento pre-

37 Vid. las resoluciones del II Congreso, en SB 1926, 159-62.

38 AMMENDE, E., «Richtlinien zur Begründung der Volksgemeinschaft), abril 1932, 45359; Schiemann, P., «Uberstaatliche Volksgemeinschaft - eine Panbewegung", Nation und Staat, abril 1932, 438-45; TÖROK. A., "Volksgemeinschaft als Rechtsidee», Nation und Staat, abril 1934, 418-28.

Hispania, LVIII/3, núm. 200 (1998) 1113-1151 
vio fallase ${ }^{39}$. El sistema de protección de minorías no colmaba las exigencias del CNE, ya que en él las minorías nacionales no eran consideradas sujetos con personalidad jurídica, sino que sólo protegía a los individuos, al estar basdo en la concepción liberal de protección de los derechos humanos. Para el Congreso, poe wl contrario, los sujetos del Derecho de Nacionalidades y del sistema de protección de minorías habían de ser las minorías nacionales en cuanto colectivos con derechos propios reconocidos ${ }^{40}$.

Como base para tal aserción se argumentaba que todas las competencias en cuestiones culturales debían ser asumidas directa y exclusivamente por las comunidades nacionales. La cultura era por definición una realidad colectiva, que necesitaba ser respaldada y conformada por un cuerpo de derechos que tuviesen como sujeto al mismo grupo étnico:

«Las tareas culturales, como sabemos, sólo pueden ser tareas comunitarias. La labor comunitaria en cuestiones nacionales y culturales es la cooperación de individuos de la misma nacionalidad, con el mismo idioma y la misma cultura. Las tareas comunitarias hacen necesarios derechos comunes para la administración autónoma [Selbstvernaltung], y el sujeto de esos derechos de autogobierno debe ser la comunidad nacional..; ${ }^{41}$.

Esa concepción era conforme con la definición orgánico-objetiva de la nación: una colectividad vinculada por una cultura, historia y características étnicas comunes. Por esa razón, el CNE rechazaba por lo general el ser denominado «Congreso de Minorías» y prefería adoptar la definición «Congreso de los Grupos Nacionales organizados», en cuanto, como recordaba Ammende en 1934, «nosotros ya entonces planteamos nuestro propósito de representar colectividades sociológicas de iguales derechos, no sólo nuestros intereses individuales, sino también los de nuestros pueblos y comunidades nacionales» ${ }^{42}$. Por razones similares, la mayoría de los integrantes y participantes en el CNE estaban de acuerdo en que el término minoría no era el adecuado para designar

39 Resolución «Wege zur Regelung von Streitigkeiten zwischen Regierungen und nationalen Gruppen", en SB 1926, 163-64.

40 Vid. por ejemplo el discurso del representante judío Nurck en el I Congreso (1925); «A pesar del gran cataclismo desencadenado para la cuestión nacional por la Guerra y sus consecuencias, sobre todo en lo referente al fortalecimien to de la voluntad colectiva, es decir, de la voluntad de una participación común en aspectos nacionales-culturales, que se manifiesta en todos los grupos nacionales, hay que decir que estos hechos no son tenidos mínimamente en cuenta en las resoluciones de los Tratados de Minorías, ya que en ellos se habla solamente de la protección de los integrantes individuales de cada minoria en lo referente al libre ejercicio de su idioma y religión, peto en ningún caso de la protección de las expresiones nacional-culturales de las comunidades en cuanto tales» (SB 1925, pág. 44). Asimismo, vid. la primera resolución del XII Congreso del CNE, 1936, en SB 1936, pág. 78. pág. 711 .

41 Intervención de H. Rutha en el XIII Congreso, en Nation und Staat, vol. X (1936/37),

42 Intervención de Amende, en SB 1934, pág. 20.

Hispania, LVIII/3, núm. 200 (1998) 1113-1151 
a grupos étnicos diferentes de los que formaban la mayoría del Estado, y prefería emplear el más específico de nacionalidad o de grupo nacional [Volksgruppe]. Entre los sectores opuestos a la denominación minoría destacaban los agrupados en torno a Werner Hasselblatt y los representantes de los alemanes de los Sudetes, para quienes aquel término expresaba una suerte de renuncia inconsciente a tomar parte en el Gobierno y dirección del Estado, y además entrañaba una connotación valorativa, de inferioridad nacional, implícita en su inferioridad numérica. Como afirmaba W. Brand en 1935,

«Hoy en día se relaciona con el término minoria solamente de modo ligero y peligroso el concepto de inferioridad. [...] El término minorías debería usarse con suma precaución. Me parece mucho más acertado hablar de grupos étnicos en Estados de otra nacionalidad, con lo que el acento y la significación de cada grupo étnico dentro del Estado común apenas se puede desviar de su significación dentro del conjunto, pues es posible que un grupo étnico, según las circunstancias, juegue un reducido papel mientras otro juege un rol decisivons ${ }^{43}$.

No obstante, el CNE no llegó a formular un concepto totalmente nuevo de términos como nacionalidad o grupo étrico, aparte de algunos intentos aislados llevados a cabo por teóricos que se movian en la órbita del Congreso, como H. Raschhofer o H. Tanzmann ${ }^{44}$. Los debates de naturaleza puramente científica se dejaban a la labor de instituciones de investigación específicas encargadas, que, de acuerdo con el CNE, habrían de definir y precisar las ideas del movimiento nacionalitario.

$\mathrm{El} \mathrm{CNE}$, sin embargo, había definido en sus reglas de funcionamiento interno algunas condiciones específicas para que un grupo étnico pudiese ser considerado como unacionalidad" y, por tanto, digna de ser aceptada en la organización a través de sus representantes. En concreto, dichas condiciones eran: 1) Los grupos étnicos en cuestión habían de poseer un grado de organización cultural y política propia dentro del Estado al que perteneciesen; y 2) debían poseer formas reconocibles de cultura diferenciada, así como los integrantes del grupo étnico estar de acuerdo mayoritariamente sobre su autoconsideración como nacionalidad ${ }^{45}$. La existencia de una nacionalidad se comprobaba mediante la constatación de su deseo voluntario y subjetivo de seguir siéndolo, lo que también se expresaría por la voluntad de sostener un idioma y una cultura diferenciadas.

43 BRAND, W., "Volksgruppe, Volksgemeinschaft und Staab, Nation tnd Staat, octubre 1935; vid. también HasselBLATT, W., "Geistige Verkehrshindernisse», Nation und Staat, vol. I $(1927 / 28), 330-35$.

44 RASCHIOFER, H., Nationalität als Wesen und Rechtsbegriff, Berlín: J. Springer, 1937; TAN. zMann, H., Die Diskussion über den Begriff der unationalen Minderbeit», Dresde: Risse-Verlag, 1932.

$45 V i d$. SB 1928, pág. 165. Realmente, estas nómas fueron elaboradas para enfrentarse a la reivindicación de los frisones del Norte (Alemania) para ingresar en el CNE en calidad de unacionalidad».

Higpania, LVIII/3, núm. 200 (1998) 1113-1151 


\section{LA AUTONOMÍA CUITURAL}

La fórmula de la «administración propia» [Selbstvervialtung] para una colectividad nacional determinada se expresaba en la solución de la autonomía cultural. Este progtama tenía tres claros antecedentes, lo que también permitía una lectura muy amplia por cada uno de los diferentes grupos nacionales, contribuyendo así a su aceptación polivalente.

a) Un antecedente claro se situaba en las teorías elaboradas en el Imperio austro-húngaro por los socialdemócratas austríacos desde fines del siglo XIX. En este aspecto, el CNE recogió y reelaboró las doctrinas y propuestas avanzadas por Otto Bauer y Karl Renner, así como por otros autores menores como Jellinek, o el ex-canciller austríaco Ignaz Seipel a comienzos del siglo XX ${ }^{46}$. La autonomía cultural basada en el «principio personabs [Personalitätsprinzip], es decir, en la adscripción individual y voluntaria a la nacionalidad, fue formulada en primer lugar en 1866 por el político liberal austríaco Adolph Fischhof, quien postulaba el establecimiento de una Ley de Nacionalidades que regulase la paridad de idiomas en las escuelas, iglesias, servicio civii, justicia y legislación ${ }^{47}$. Durante la segunda mitad del siglo XIX, y tras el Compromiso (Ausgleich) de 1867, tuvieron lugar en el Imperio austro-húngato diversas tentativas institucionales y proyectos de ley nunca puestos en práctica, que aspiraban a asegurar una efectiva protección de minorias basada en principios semejantes ${ }^{48}$. Y casi cuarenta años más tarde, en 1902, el líder y teórico de la socialdemocracia austríaca Karl Renner desarrolló y profundizó el concepto de la autonomía culturaí, que redefinió en 1918. El también socialdemóctata Otto Bauer retomó de nuevo ese legado doctrinal en 1923/24 ${ }^{49}$.

46 Jellinek, especialmente, en su libro Das Recht der Minoritäten, Viena: A. Hölder, 1898, se mostraba favorable a arreglos constitucionales que concediesen un derecho de veto a los grupos nacionales menores, para asi posibilitar que el clásico criterio liberal de la ley de las mayorias fuese operante en Estados multinacionales. Vid. asimismo RASCFHOFFER, H., «Rechtswissenschaft und Nationalitätenforschung», Nation und Staat, febrero 1934; id., «Das altösterreichische Nationalitätenrecht und das Minderheitenrecht der Gegenwarbs, Deutsche Arbeit, mayo/junio $1928,221-25$, y «Das altösterreichische Nationalitätenrecht und die deutschen Volksgruppen nach 1918", en WittMann, P., y GRAF BeThlLEN, S. (eds.), Volksgruppenrecbt. Ein Beitrag zur Friedenssicberung, Munich/Viena: Günter Olzeg Verlag, 1980, 53-69; asimismo, HugELManN, K.G. (ed.), Das Nationalitätenrecht des alten Österreich, Viena/Leipzig: Braumüller, 1934.

${ }_{47}$ Vid. FischitofF, A., Österreich und die Burgschaften seines Bestandes, Viena: Wallishausser'sche Buchhandlung, 1866. Fischhof estaba también a favor de fundar una suerte de cuerpos legislativos que pudiesen deliberar juntos, pero que votarían separadamente en curiae nacionales. Esta propuesta era a su vez deudora de la Litio in Partes, un articulo del Tratado de Westralia que regulaba la coexistencia de confesiones religiosas.

4B Vid. STOURZH, «Problems of conflict resolution», pág. 75, y KANN, R.A., «Die Habsburgermonarchie und das Problem des übernationalen Staates», en WANDRUSZKA, A. y URBANITSCH, P. (eds.), Die Habsburgermonarcbie 1848-1918. Band II: Venvaltung und Recbtswesen, Viena: Verlag der osterteichischen Akademie der Wissenschaften, 1975, especialmente 39-47.

49 SPRINGER, R. (pseudónimo de Katl Renner), Der Kampf der österreichischen Nationen um den Staat, Leipzig/Viena: Franz Deuticke, 1902; id., Das Selbstbestimmungsrecht der Nationen in besonderer Anvendung auf Osterreich, Leipzig/Viena: Franz Deuticke, 1918; BAUER, O., Die österreichische 
La concepción de la autonomía cultural habría de sobrevivir por varios años y dejar una profunda huella en la historia de las ideas, desde los nacionalistas judio-sionistas hasta los mencheviques. Igualmente, alcanzó una expresión y formulación legal reconocida por breve tiempo en la fugz República ucrania de 1918. Un modelo diferente, pero también operante, para el CNE era el ofrecido por el Estado pluriétnico suizo, paradigma, en este caso, de convivencia federativa basada en la autonomía territorial de varios grupos étnicos dentro de un mismo Estado ${ }^{50}$.

Renner consideraba que la adscripción de los ciudadanos de un Estado a cada nacionalidad debía ser individual e independiente del territorio que habitasen. Por ello, consideraba el uprincipio personal» como el mecanismo que podría facilitar la convivencia entre diferentes nacionalidades. Allí donde grupos étnicos diferenciados se distribuyesen de forma entremezclada y mixta, las demarcaciones territoriales crearían por fuerza mayorías y minorías. En consecuencia, el único medio para defender los intereses de cada uno de los grupos étnicos era constituir naciones a través de asociaciones de individuos [Personalverband] y no como áreas de dominación territorial. Esas naciones disfrutarían de autonomía cultural completa e igualdad mutua. Incluso si la concepción de Renner contempla una autonomía radical, ésta se restringe a la esfera cultural y educacional. El Estado debería ocuparse únicamente de las cuestiones materiales, estando facultado solamente para intervenir a favor de las nacionalidades más pobres e incapaces de organizar autónomamente su propia vida cultural. Para Renner, las naciones se constituían igual que confesiones religiosas: como corporaciones sujetas al Derecho público, siendo considerada la pertenencia a una nación como una decisión personal, basada en el principio de libre asociación de los individuos, sin importar su lugar de residencia. Las naciones se dotarían así de sus propias instituciones en el ámbito legislativo, ejecutivo y administrativo en todo lo referente a educación y cultura. Por otro lado, todas las naciones que formaban un Estado debían participar con equidad en el Gobierno del mismo, estando representadas de acuerdo con un criterio proporcional en todos sus niveles, para lo que proponía la introducción de un sistema de representación proporcional a través de «listas nacionales». Su objetivo era despolitizar las cuestiones nacionales, eliminando las disputas interétnicas sobre idioma, cultura o educación. Con ello, la escena política se teduciría a la confrontación entre intereses, programas y clases sociales ${ }^{51}$.

Revolution Viena: Wiener Volksbuchhandlung, 1923, e id., Die Nationalitätenfrage und die Soztaldemokratie, Viena: Wiener Volksbuchhandlung, 1924. Sobre el contexto histórico, vid. MOMMSEN, H., Arbeiterbewegung und nationale Frage, Göttigen: Vandenhoeck \& Ruprecht, 1979. Sobre Bauer, vid. Nimn, E., Manxism and Nationalism. Theoretical Origins of a Political Crisis, Londres: Pluto, 1991, 119-84, y García PElAYO, M., El tema de las nacionalidades. La teoria de la nación en Otto Bauer, Madrid: Fundación Pablo Iglesias, 1979.

50 Vid. SCHIEDER, T., «Die Schweiz als Modell der Nationalitätenpolitik» [1958], en T. SCHIEDER [O. DANN y H.-U. WEHLER, eds.], Nationalismus und Nationalstaat, Göttingen: Vandenhoeck \& Ruprecht, 1992, 303-28, así como KoliN, H., Nationalism and Liberty. The Swiss Example, Westport, Co.: Greenwood, 1978.

51 RENNER, Dar Selbstbestimmungsrecbt, passim.

Hipaania, LVYII/3, núm. 200 (1998) 1113-1151 
En consecuencia, la articulación de la esfera pública dentro de un Estado multinacional tenía que llevarse a cabo en tres niveles: el del Estado en sí; el de cada uno de los territorios, entendidos como agrupaciones regionales de corporaciones nacionales; y el de las nacionalidades supraterritoriales. Las nacionalidades disfrutarian de una administración autónoma en lo relativo a cuestiones culturales; en el caso de que coexistiesen zonas de poblamiento étnico mismo con zonas de poblamiento étnico homogéneo dentro de un mismo Estado, se procedería a la combinación de autonomías territoriales y personales ${ }^{52}$.

Los socialcristianos austríacos también llevaron a cabo desde comienzos del siglo XX la elaboración de una doctrina para el Estado multinacional, que en su caso (H. Lammachs, Ignaz Seipel) también se concebía como un posible modelo para una reorganización europea en el futuro. El canciller austríaco Iqua Seioel trazaba una necesaria separación entre Nación y Estado en el área centroeuropea, de la esfera cultural y la esfera polititica, de un modo análogo a las teorías de sus rivales austromarxistas ${ }^{53}$.

Tras la I Guerra Mundial, las propuestas de Renner y Bauer gozaron de amplia difusión entre muchos líderes e intelectuales de diversas nacionalidades centroeuropeas. Por ejemplo, el autor checo Emanuel Rádl publicó en 1928 en alemán una interesante interpretación de las rivalidades nacionales surgidas entre alemanes y checos dentro del nuevo Estado checoslovaco, y postulaba una solución inspirada en las teorías austromarxistas. Rádl denunciaba la postura represiva hacia los alemanes de los Sudetes adoptada por los triunfantes nacionalistas checos tras 1919 , y reivindicaba una separación entre lo «nacional» y lo "estatai». La solución, para él radicaría en la aplicación general de una autonomia nacional (término con el que designaba a la autonomía cultural) para el conjunto del territorio del Estado, que convertiría a las nacionalidades en «unidades constitutivas del Estadon, a partir de acuerdos mutuos y voluntarios, por Io que hablaba de un «Estado contractuab» [Vertragsstaat ${ }^{54}$. El alemán de Transilvania A. Poperici elaboró también una teoría de los derechos de las nacionalidades, que consideraba que el futuro de Europa habría de ser un mosaico de diferentes Estados plurinacionales que sustituirían a los antiguos Imperios, y que se basaria en un generoso y generalizado modelo de autonomía cultural para las minorías nacionales ${ }^{55}$. Se podría citar una pléyade de autores menores.

b) Una segunda tradición doctrinal de defensa de la autonomía cultural, el principio personal y de la separación entre nación y Estado se hallaba también

52 Vid. Schieder, T., "Idee und Gestalt des übernationalen Staates seit dem 19. Jahrhunderbs [1957], en DANN y WEHLER (eds.), Nationalismus, 38-64.

53 Vid. vON KLEMPERER, K., Ignaz Seipel. Staatsmann einer Krisenzeit, Graz: Styria, 1976 [Princeton, 1972], 53-61.

54 RADL, E., Der Kampf zpyischen Tscbechen und Deutschen, Reichenberg: Stiepel, 1928. El libro tuvo una acogida muy favorable en los ambientes de apoyo a las minorías germanas dentro de Alemania: vid. Peters, G., «Nationalstaat oder Vertragsstaat?. Der tschechische Professor Rádl über das Nationalitätenproblemv, Der Auslandsdeutsche, XII: 13 (1929), 422-25.

55 RASCHHOFleR, «Das altösterreichische Nationalitätenrechb», pág. 60. 
en las soluciones propuestas desde fines del siglo XIX por varios teóricos nacionalistas judío-sionistas y asimilacionistas, así como por partidos socialistas judíos desde 1890, como el Bund, en buena parte muy influidos por las ideas de Renner, que parecian especialmente adecuadas para las dispersas poblaciones judías de los imperios multinacionales ruso y austrohúngaro ${ }^{56}$. Teóricos como Zhilowsky, Dubnow o Nathan Birnbaum habían formulado con anterioridad a la Gran Guerra diversas teorias acerca de las aspiraciones a la autonomía «nacional-cultural» para las minorías hebreas, comprendiendo en algunos casos la esfera política y en otros sólo la esfera cultural ${ }^{57}$. Durante la Guerra Mundial, las organizaciones judias internacionales - tanto europeas como americanas- se comprometieron en la lucha por garantizar mayores derechos nacionales para los hebreos tras el fin del conflicto: en la II Conferencia de las Nacionalidades de Lausanne (1916), la representación del Comité Judío de Suiza expresó una confusa aspiración a la autodeterminación en materias como educación, idioma, costumbres y cultura ${ }^{58}$. Igualmente, la organización socialista Poale Zion expuso en noviembre de 1915 y en 1917 su reivindicación de que el derecho de autodeterninación nacional para las minotías judias en Estados plurinacionales les permitiese «conservar su vida nacional específica, garantías legales para su existencia nacional y desarrollo intelectual sin trabas, autogobiemo en cuestiones nacionales e igualdad nacional en el Gobierno del Estado, región y ciudad» ${ }^{59}$. En las resoluciones del «Congreso de los Pueblos» celebrado a iniciativa de la Rada ucrania en Kiev en septiembre de 1917, se reconocia el derecho de las minorías judías a disfrutar de una amplia autonomía personal de carácter extraterritorial; y la efímera República Ucrania de 1918 reconoció tambiér a los hebreos el derecho a una autonomía cultural de base no territorial, mediante Consejos Judios encargados de administrat cultura y educación, cuya comunicación con el Gobierno se establecería a través de un ministro de Asuntos Judios ${ }^{61)}$. El cul-

56 JAnowsku, O., The Jens and Minority Rights (1898-1919), Nueva York: AMS Press, 1966 [1933], pág. 32 y ss.; Levene, M., War, jews and the New Europe, Londres: Oxford UP/The Littman Library, 1992, 165-67. No obstante, el mismo Renner (Das Selhstbestimmungsrecht, 45-46) habia resaltado las diferencias existentes entre sus propuestas y la interpretación de sus teorías por los líderes judios de Europa Oriental, en cuanto lo que estos últimos pretendian no era la coparticipación de diferentes nacionalidades dentro de un mismo Estado, sino la posesión de una esfera jurídicopública libre de la influencia del Estado.

57 De hecho, el debate teórico principal en esta época entre los medios políticos e intelectuales judios europeos se centraba en tres cuestiones: autonomía y derechos nacionales, sionismo y la coexis-

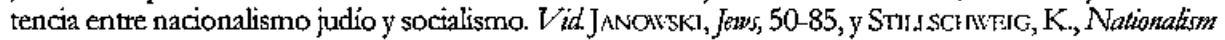
and Autonomy among Eastern Exropean Jewry, Nueva York: American-Jewish Committee, 1944.

58 Compte rendu de la IIme Conférence des Nationalités, Lausana: Office Centrale des Nationalités, 1917, 22-24, 32-33 y 145-52.

59 Citado por JANOwSKI, Jeyss, pág. 195. El pronunciamiento de Poale Zion fue adoptado por el Comité holandés-escandinavo de la Internacional Socialista como principio de aplicación general.

(iv) Srojko, W., «The Attitudes of the Russian Provissional Government towards the NonRussian Peoples of its Empires, Tesis Doctoral, Universidad de Columbia (Nueva York), 1969, 250 . 51; Gol DMMn, S.I., Jewish National Awtonomy in Ukaine, 1917-1920, Clicago: Chicago UP, 1968.

Iliphania, LVIII/3, núm. 200 (1998) 1113-1151 
men de toda esta actividad internacional será sin duda el importante papel jugado en las negociaciones de paz y en el surgimiento de los Tratados de Minorías por el CDJ y por Lucien Wolf —este último en representación de las organizaciones hebreas británicas y francesas-. No obstante, si bien las organizaciones judías añotaban en su mayoría un Imperio supranacional como el austrohúngaro, considerado el mejor garante de los derechos culturales de las minorias.

Aunque las vacilaciones entre autonomía territorial, política y autonomía cultural eran numerosas, las organizaciones judias, y particularmente las menos proclives al sionismo, se mostraban favorables a la solución de la autonomía cultural como medio de mantener los derechos de las minorias hebreas en Europa Centro-oriental y de garantizarles un tratamiento ecuánime por parte de los nuevos Estados surgidos en 1918-19. En los primeros años 20, ideólogos como E.B. Sadinsky insistieron de nuevo en la necesidad de separar la nacionalidad y el Estado. En su obra de 1921 La sociedad nacional Sadinsky destacaba que el Estado debía preservar su soberanía en la esfera económica, en los aspectos políticos y legales y en las «funciones de la civilización técnica», mientras la nación debía reducir su soberanía al ámbito cultural y educacional. Ahora bien, también consideraba que la nación debía poseer medios de coerción y competencias políticas para defender aquella esfera de poder, ya que un problema adicional era que las naciones se extendían sobre las fronteras de los Estados existentes. Por ello, defendía que «cada nación debe, junto a la soberania nacional interterritorial sobre todos sus miembros esparcidos por el mundo, ejercer también en un territorio determinado y delimitado una soberanía estatal-territorial sobre todos los habitantes de ese territorion, de modo que cada nación tuviese también "su patria histótica, como sede de su soberanía tanto nacional-interterritorial como estatal-territorial», lo que denominaba «centro nacional». Con ello, Sadinsky formulaba una teoría que le permitía compaginar la fe en la autonomía cultural con su militancia sionista, que le llevaba a justificar la necesidad de que el pueblo judío contase con un Estado propio en Palestina, que jugaria el papel de centro de la comunidad nacional judía ${ }^{61}$. Este modelo ejerció gran influencia sobre algunos de los principales teóricos del CNE (especialmente sobre Schiemann, confeso admirador de las teorías del sionista), particularmente en lo referente a la separación del principio territorial y nacional. Sadinsky, de hecho, estuvo en contacto con los líderes del CNE, y se identificó explícitamente con el programa de la organización, acudiendo al III Congreso de Nacionalidades Europeas de 1927, tras el que intentó sin éxito convertirse en el impulsor de su programa político e ideológico ${ }^{62}$.

61 SADINSKY, W.B., Die nationale Sozietät. Beitrag zur Lösung der Judenfrage im Zusammenhang mit dem allgemeinen nationalen Problem, Heidelberg: Verlag der «Freien Zionistischen Blättebs, 1921, pág. 18 ss. y 35 . Sadinsky establecía hasta nueve puntos en los que se podía llevar a efecto detalladamente la separación y nivelación de funciones entre Estado y nación.

62 Entusiasmado ante lo que consideraba una expresión organizada del nuevo problema nacional creado tras la Guerra, dirigió en diciembre de 1927 a varios dirigentes del CNE un amplio memorándum en el que, tras asegurar que la organización nacionalitaria había pasado por una 
c) Una tercera tradición se encontraba en la tradicional autonomía corporativa de los baltoalemanes. Para amplios sectores de los círculos dirigentes de las minorías germanas, la fórmula de la autonomía cultural les permitia desafiar la equivalencia entre Nación y Estado, consiguiendo así un reconocimiento doble como ciudadanos de sus nuevos Estados y de Alemania (que les permitía disfrutar, en base al ius sanguinis, de plenos derechos como ciudadanos si se reintegraban al Estado alemán). Para ello, en muchas ocasiones las nuevas teorias de los socialdemócratas austríacos eran combinadas convenientemente con la tradición propia de pensamiento corporativo, especialmente presente entre los baltoalemanes.

Las minorías alemanas de los Estados bálticos habían desarrollado una forma de organización desde la Edad Media, basada en corporaciones étnicas, dentro de las cuales se subdividían a su vez en corporaciones y gremios profesionales, así como en corporaciones educativas, religiosas y culturales, regidas por leyes específicas reconocidas por el Estado ruso, que reconocía la tradicional fidelidad al zar de los baltoalemanes (se trataba del llamado Landesstaat, un estatus autónomo privilegiado dentro del Imperio ruso). No obstante, aquéllos tuvieron que enfrentarse desde 1881 a las crecientes medidas «rusificadoras» del Imperio zarista y a la presión de los nacionalismos estonio y letón, lo que a su vez fortaleció un sentimiento de identidad nacional alemán personificado en sus derechos e instituciones ${ }^{63}$. Con ello, los baltoalemanes consideraban al Estado como un conjunto de "corporaciones personales" y negaban la soberanía del Estado liberal.

Aunque después de 1918 los Estados estonio y letón suprimieron esas instituciones, el pensamiento corporativo permaneció vivo, como una propuesta activa y transformada en fórmula de organización de las minorías nacionales en un Estado multinacional ${ }^{64}$. El diputado estonio-alemán Werner Hasselblatt era el

primera fase uformativa» y especulativa, en la que se habia dejado llevar por una excesiva fe en la SdN y los Tratados de Minotias, proponia que el CNE abordase una segunda fase en la que habria de convertirse en un «Congreso de las $\mathrm{Naciones}$ de Europa» que incluyese delegaciones de las nacionalidades mayoritarias en cada uno de los Estados, para llevar a cabo la aplicación práctica de su programa de «sociedad nacionabs. Tan utópico proyecto, como era de esperar, no fue tenido en consideración por el Congreso. Vid. carta de E.B. Sadinsky a Vilfan, Zürich, 15.9.1927, y memorándum de Sadinsky, Denksctorift an den worbereitenden.Ausschuss fïr den vierten Nationalitatenkongress, Zürich, 6.12 .1927 (BK-AV).

63 Vid. Rotrusels, H., «Reich, Staat und Nation im deutschbalcischen Denken», en id. (ed.), Bismarck, der Osten und das Reich, Darmstadt: Wissenschaftliche Buchgesellschaft, 1962 (2. ed.), 182-204; GARLEFF, M., «Relations between the Political Representation of the Baltic Provinces and the Russian Government, 1850-1917\%, en G. ALDERMAN (ed.), Governments, Ethnic Groups and Political Representation, New York/Aldershot: New York UP/Dartmouth, 1993, 20138, y SCFILAU, W., Die Deutschbalten, Munich: Langen Müller, 1995, 59-83.

64 Asi, por ejemplo, el baltoalemán Paul Rohrbach, cercano a la crevolución conservadora», explicitaba su defensa de la doctrina corporativa como una crítica más profunda al sistema parlamentario y la garantía de un puesto director al «estamento medio educados [gebildeter Mittelstand) dentro de una sociedad orientada con criterios orgánicos (vid. GRUNDMANN, K.H., Deutschtumspolitik zur Zeit der Weimarer Republik. Eine Studie am Beispiel der deutschen-battischen Minderbeit in Estland und Letlland, Hannover-Dören: Hirschheydt, 1977, 427-28). Para una curiosa elaboración teórica del pensamiento corporativo en combinación con las teorias austromarxis-

Hitpania, 1,VIII/3, núm 200 (1998) 3113-1151 
principal valedor de esta neointerpretación de las tradiciones corporativas baltoalemanas dentro del $\mathrm{CNE}$, según la cual las minorías alemanas debían «aspirat a su teunión en un estamento nacional, en el sentido de una corporación orgánica de Derecho público con un punto de vista nacional que fuese el fundamento de la comunidad de intereses, de vida y de pensamiento, con una aspiración a derechos conjuntos y la disposición a un trabajo y reponsabilidad conjunta», cuya naturaleza orgánico-corporativa le permitiría sobrevivir a los avatares políticos y aspirar a algo más que a la mera preservación cultural ${ }^{65}$. En este sentido, se interpretará la ley de autonomía cultural estonia de 1925 como una manifestación de aquella tradición, por lo que sería equiparable con eila en una forma renovada y recomendable como modelo para permitir «la convivencia en un destino común en el conjunto de Europa orientab, ${ }^{66}$. El redactor del órgano oficial de la organización europea de las minorías alemanas (la revista Nation und Staat) Arnold Weingärtner describió años más tarde la apelación recurrente de los líderes de las minorías alemanas a las tradiciones corporativas. Éstas no implicarian siempre una vuelta al Estado corporativo, sino que eran consideradas una consecuencia de la preeminencia de la nación [ $\mathrm{V}$ olk] sobre el vínculo social [Gesellschaft], pasando a concebir la sociedad como una parte integrante de la nación, pero no como su sustituto; igualmente, la apelación a las tradiciones corporativas lievaba a negar las divisiones sociales de clase dentro de la nación, compuesta de estamentos y "capas» sociales ${ }^{67}$.

Aunque en el compromiso entre alemanes y checos de Moravia de 1905 (el Ausgleich moravo) se puso parcialmente en práctica este sistema, al permitirse la elaboración de «catastros» de nacionalidades mediante inscripción individual voluntaria en cada municipio, sistema que fue también aplicado en Bukovina en 1910, la plasmación más próxima y completa de las ideas austromarxistas parecía ser a principios de los años 20 la ley estonia de autonomía cultural. Esa solución, a ojos del movimiento nacionalitario europeo, se convirtió en un modelo exportable a escala continental, con lo que su aplicación general a todos los Estados multinacionales de Europa pasó a constituir una parte importante del programa del CNE. A pesar del hecho de que Estonia era un pequeño Estado en el que las minorías nacionales no totalizaban más de 10-12.000 individuos, la satisfactoria evolución seguida por la autonomía cultural en el área báltica reforzó la convicción de los líderes del CNE acerca de la bondad de su aplicación, considerándola como un primer signo de la institucionalización de los problemas de nacionalidades partiendo de un acuerdo pacífico entre las mi-

tas, wid. tambien TEZNER, H,Das ständisch-monarchische Staatsrecht und die österreicbische Gesamt-oder Länderstaatsidee, Viena: Hölder, 1915.

65 HASSELBI.ATT, W., «Die Durchführung der Kulturautonomie in Estland», en K.C. vON LoEscir (ed.), Staat und Volkstum, Breslau: Hirt, 1926, 156-61.

66 Lo que defendía todavia en 1935 Ro'ilHFes, H., «Das Problem des Nationalismus in Ostens, en id., Ostraum, Preußentum und Reicbsgedanke, Leipzig: Hintrichs, 1935, $180-88$. 42.

67 Weingätner, A, wNation und Staats. Eine Monographie, Viena: Braumüller, 1979, pág.

Hitpania, L.VIII/3, núm 200 (1998) 1113-1151 
notías y el Estado ${ }^{68}$. Con esa institucionalización, el Estado desaparecía de la esfera cultural, siendo sustituido por «cuerpos administrativos» [Selbstverwaltungskörper] con personalidad jurídica reconocida, fuese como una corporación del grupo étnico en cuestión, fuese como una asociación libre de individuos. Esas organizaciones se basarian en criterios territoriales o personales, dependiendo de las características específicas del poblamiento de cada una de las nacionalidades ${ }^{69}$. Las ventajas de este sistema evitarian la tentación de de aspiraciones irredentistas o separatistas por parte de las minorías nacionales, como ya expresaba en 1926 uno de los ideólogos más influyentes del movimiento nacionalitario, el líder de los alemanes de Eslovenia Camilo Morocutti ${ }^{70}$. Con ello, se garantizaría también la coexistencia y cooperación leal entre todas las nacionalidades que habitasen un mismo Estado, y se conseguiría un fin más amplio, la existencia de una enacionalidad libre en un mundo por encima de las fronteras estatales", lo que, según Otto Junghann, enlazaría con el auténtico sentido del principio de autodeterminación de los pueblos ${ }^{71}$.

Las corporaciones nacionales no desafiarian la preponderancia del Estado en el terreno político, ya que el CNE aspiraba teóricamente a una despolitización de la cultura. Esa separación entre cultura y política, sin embargo, no implicaba que los grupos étnicos como tales renunciasen a toda forma de reivindicación política en su relación con el Estado; pero sus aspiraciones políticas no se canalizarian a través de las corporaciones o instituciones encargadas de gestionar la autonomía cultural. En este sentido, las experiencias del desarrollo de la ley estonja de 1925 sirvieron para justificar la viabilidad de las propuestas del CNE, si bien desde los años 30 tendió a prevalecer en la organización una imagen estereotipada e idealizada del modelo báltico ${ }^{72}$.

68 Como H. Kraus expresaba ya en 1927, «con ello [la autonomia cultural estonia] se ha creado una nueva área tanto en el derecho internacional como en el derecho estatal, en la que ningún Estado debería dejar de participan (Kraus, H., Das Reibt der Minderbeiten, Berlin: Heymann, 1927, pág. 199). Vid. también FrIEDMAN, S., Le probleme des minorités ethniques et sa solution par l'autonomie et la personification, París: s.ed., 1927.

69 SB 1925, primera resolución. Semejantes principios fueron reiterados en lo sucesivo en la actividad del CNE, en los congresos de 1926, 1931 y 1933, además de ser defendidos por varios representantes de diversas racionalidades. Desartollos teóticos más profundos se pueden encontrar (con referencias comparativas a otros Estados, incluidos los Dominios británicos) en DöRGF, $H$., Der autonome Verband im geltenden Staats- und Völkerrecht, Viena: Braumüller, 1931, así como en MiNTZ, M., Die nationale Autonomie im System des internationalen Minderbitenrechtes, Riga: Walters \& Rapa, 1927, y GERßER, H., Kulturautonomie als Eigenart miderbeitenrechticher Ordnung, Berlin: Stilke, 1926.

70 Morocu'rT, C., "Gibt es eincn wirksamen Schutz der Minderheiten?", Neue Freie Presse, 3.9.1926.

71 Junghann, O., «Die Minderheit in Staat und Welo, Nationt und Staat, julio 1929, pág. 671.

72 Vid. por ejemplo el discurso de Ammende ante el VII Congreso del CNE (1931), en SB 1931, 74-78. El CNE había pedido a E. Maddison, secretario general del parlamento estonio, y a Martna, líder del partido socialista estonio, que expusiesen los resultados de la ley de autonomia cultural en aquel país a los seis años de su promulgación. Maddison también informó sobre la experiencia bajltica en el artículo "Die Erfahrungen mit der Kulturautonomie in Estland», Nation und

Hipania, LVH11/3, núrn. 200 (1998) 1113-1151 
El CNE se mostraba abierto a aceptar que las condiciones en las que vivjan las diferentes minorías étnicas no eran siempre comparables. En consecuencia, en el caso de minorías que habitaban en zonas de poblamiento étnicamente homogéneo donde constituían una amplia mayoría, la autonomía cultural podría ser aplicada según un criterio territorial, aunque el CNE expresaba una preferencia general por el principio personal. Cuando el poblamiento étnico era dispersa, la autonomía se pondría en práctica siguiendo el criterio personal. Esa duplicidad de soluciones era necesaria para que dentro del CNE pudiesen participar representaciones de nacionalismos como el catalán o el ucranio, por ejemplo, así como de minorías nacionales de zonas de poblamiento más o menos «homogéneo» como los alemanes de los Sudetes y los carpato-ucranios de Checoslovaquia ${ }^{73}$. En general, las posiciones de las representaciones de cada una de las minorias dentro del CNE frente a la fórmula de la autonomía cultural variaban de acuerdo con su nivel de potencialidad económica y cultural, su composición social y su experiencia de autoorganización política. En este sentido, las minorías judías y germanas se situaban entre los más decididos defensores de la autonomía cultural, con la excepción de los alemanes de Hungría, muy condicionados por la política asimilacionista del régimen de Budapest, pero también por la personalidad de su máximo líder (hasta su muerte en 1933) Jacob Bleyer, quien era partidario de una magiarización de la intelligentsia germana y de la preservación de un completo sistema escolar para las minorias alemanas en las zonas rurales, con lo que la minoría alemana podría «participat» en el Gobierno del Estado en pie de igualdad con los magiares. En el caso hebreo, la aspiración a la autonomía cultural dentro de las fronteras de los Estados existentes se correspondía con sus características peculiares (sin Estado connacional, aparte de la esperanza que para los sionistas representaba Palestina), y, como vimos, gozaba ya de una amplia tradición doctrinal desde fines del siglo XIX. Los nacionalistas catalanes defendían el principio de la autonomía cultural, si bien al mismo tiempo defendian su compatibilidad con la autonomía territorial para aquellas nacionalidades de poblamiento homogéneo, solución que evidentemente preconizaban para sí mismos. También mostraban su preferencia por la autonomía territorial los delegados bjelorrusos de Polonia, los ucranios de Polonia y Rumanía y los rutenos de Checoslovaquia. Los delegados magiares se caracterizaban, por el contrario, por su entusiasta defensa de la autonomía cultural, mientras los representantes de las minorías eslavas tendían a mantener posiciones opuestas a la misma: si los representantes de los rusos de Estonia adoptaban, sobre todo M. Kurtschinsky, una postura favorable a la autonomía cultural, otros veían en esa fórmula un in-

Staat, vol. IV (1930-31), 385-89, destacando que las relaciones entre estonios y baltoalemanes habian mejorado ostensiblemente gracias a la autonomia cultural. Concluia que da administración propia de las minorias étnicas no aísla a las nacionalidades, ni contribuye a su enfrentamiento mutuo, sino que las educan en un sentido favorable a la ciudadanía estonia, es decir, educan a sus integrantes como leales ciudadanos de Estonias.

73 Vid. por ejemplo la 3." resolución del IX Congreso (1933), en SB 1933, 98-99. 
strumento para fomentar el irredentismo y la traición al Estado entre las minorías ${ }^{74}$.

La división de opiniones acerca del principio de la autonomía cultural se reveló con crudeza con ocasión de las controversias que tuvieron lugar en 1927-28 alrededor de la admisión de la minoría frisona del norte (Alemania) en la organización. En esa polémica, el papel principal correspondió a la organización representativa de las minorias no germanas de Alemania (sorabos, lituanos, polacos, frisones y daneses), la Unión de las Minorías Nacionales de Alemania [Verband der Nationalen Minderbeiten Deutschlands, VNMD], así como a los representantes polacos, quienes esgrimían tres argumentos principales contra el principio de la autonomía cultural: 1) la autonomía cultural tendría el único fin de crear Estados dentro de otro Estado, lo que favorecía la penetración de los Estados connacionales de las minorias en los asuntos internos de otros países; 2) esa fórmula servía mucho mejor a los intereses de las minorias alemanas por ser «minorías fuertes» económica y socialmente, o por gozar del apoyo de un fuerte Estado connacional, ya que sólo ellas podrian mantener una red de educación privada; y 3) se rechazaba la necesidad de inscribirse en un Catastro o registro de nacionalidades, por hacer pública la adscripción nacional de cada individuo. Los daneses de Schleswig meridional, por ejemplo, temían que la autonomía cultural se convirtiese en un arma de doble filo que permitiese una intromisión de Alemania en los asuntos internos de la más débil Dinamarca, mientras a Betlín poco le podía inquietar la penetración del Gobierno de Copenhague. Y la VNMD, a través de su órgano Kultumvebr, consideraba que la autonomía cultural era un instrumento de ulteriores objetivos ocultos, como el cambio de la pertenencia estataly ${ }^{75}$. Para este órgano, la idea de la autonomía cultural habría nacido exclusivamente entre los círculos revisionistas de la Alemania de Weimar, con el fin de perpetuar la diferencia entre minotías «fuertes» y «débiles» ${ }^{76}$. Las minorías polacas, obedeciendo en parte consignas del Gobierno de Varsovia, también se opusieron tenazmente a la autonomía cultural, y avanzaron una tímida solución alternativa, consistente en la "coparticipación» de minorías étnicas y mayorías mediante el diálogo y el acuerdo para poder poner en práctica un sistema educativo específico para las minotías, pero que estuviese bajo la autoridad directa y financiación del Estado ${ }^{7}$.

74 SirRA, T., «The Volksdeutsche Kameradschaft and the Swabian Demands on the Eve of World War Il", East Central Europe/Europe du Centre-Est, 12:2 (1985), 146-63 (especialmente, pág. 149); discursos de Maspons i Anglasell en SB 1926, 20-22 y SB 1931, 10-12; discursos de A. Klinowiczs (SB 1933, pág. 38), de V. v. Saloziccky (SB 1933, pág. 35) y de J. Kurtjak (SB 1928, pág. 146); discurso de Flaschbarth en el I Congreso, en SB 1925, paig. 56; discurso de Kurtschinsky en SB 1931, 80-82.

75 Rerup, L., y DoEge, I., "The Schleswig-Holstein Question to 1923», en Smith, P. (ed.), Ethnic Groups in International Relations, Nueva York/Aldershot: New York UP/Dartmouth, 1991, 85-132 (especialmente 102-03); Kultunvebr, 1 (1926), pág. 49.

76 SKALA, J., «Starke und schwache Mindetheiten», Kuhturwehr, 1 (1927), 1-9; J. FENDIN, "Minderheitenpolitik im Dienste staatspolitischer Interessen», Kultwrwebr, 2 (1927), 306-09.

77 Vid. las críticas a esta fórmula de ScrmemanN, P., «Die Spaltung im Nationalitätenkongreß», Nation und Stat, vol. I (1927/28), 158-63.

Higpania, JVIH/3, núm. 200 (1998) 1113-1151 
Por su parte, los representantes de las minorías checas, eslovenas y croatas de otros Estados mantuvieron una actitud más flexible. Aunque consideraban por lo general que la fórmula de la autonomía cultural no era suficiente para las minorías débiles demográfica y económicamente (por ejemplo, los eslovenos de Italia), nunca se posicionaron en contra del principio general de la autonomía cultural como solución válida para la cuestión de las nacionalidades en Europa Centro-oriental. Incluso, los representantes de los eslovenos de Italia mantuvieron repetidamente en sus intervenciones, especialmente Vilfan y Besednjak, la defensa de una generalización de la autonomía cultural a todos los Estados europeos como garantía de una Europa en la que las rivalidades nacionales desaparecerían ${ }^{78}$.

Un último punto de debate doctrinal, directamente vinculado con la cuestión de la puesta en práctica de la autonomía cultural, consistía en los criterios que habrian de determinar la pertenencia a una nacionalidad. Aquí se enfrentaron dos principios dentro del CNE: el objetivo y el volitivo. Algunos representantes mostraton preferencia por el principio democrático-subjetivo, mientras otros preferían definir la nacionalidad de modo orgánico e independiente de la voluntad humana. $\mathrm{L}$ a adhesión a uno $\mathrm{u}$ otro principio no estaba directamente relacionada con la nacionalidad de los grupos participantes: las minorias alemanas tendieron a apoyar el principio subjetivo [Bekenntnisprinzip] en muchas ocasiones, salvo los representantes de la minoría alemana de Hungría (Jacob Bleyer), quienes preferian el principio objetivo ${ }^{79}$. Por el contrario, los representantes de la mayoría de las minorias eslavas se mostraban más inclinados a preferir el criterio objetivo, especialmente los de las minorías eslavas de Austria y Alemania. La división en este aspecto parecía reflejar más bien la fuerza demográfica y económica de cada una de las minorías nacionales representadas: los grupos étnicos con una notable organización cultural y conscientes de poseer un idioma de prestigio (alemanes, p.ej.) no siempre necesitaban recurrir a factores orgánicos; por el contrario, las minorías cultural, política y numéricamente más débiles necesitaban apelar a criterios que las defendiesen de la presión asimiladora de Estados más fuertes. Sin embargo, el CNE como organización se decantó mayoritariamente por la opción subjetiva: la decisión personal del individuo lo hacía integrante de una minotia nacional. Se consideraba además que el principio organicista supondría una vía abierta a la vulneración del principio de la libertad individual e incluso para la coacción violenta de los miembros de las minorías por parte de los Estados o incluso de los $\mathrm{Mut}$ terländer. En las resoluciones de su II Conferencia (1926), el CNE acordaba que «La libre adscripción de cada individuo a una nacionalidad y, en la medida en que se instaura un censo de nacionalidades, la inscripción en un registro no debe ser puesta en cuestión’ ${ }^{80}$.

78 Vid. por ejemplo los discursos de Vilfan y Besednjak en el I Congreso del CNE, en SB $1925,50-53$

7) BLEYER, J., «Nation, Volk, Nationalitäb, Nation und Staat, vol. 3 (1929/30), 285-87.

80 Primera resolución, en SB 1926, pág. 158. 
En la Sección de Minorías de la SdN, la solución de la autonomía cultural era contemplada con sumo escepticismo. En este aspecto destacaron las observaciones de $M$. Krabbe, quien a petición del director de la sección, el español Pablo de Azcárate, redactó en 1931 un informe acerca de las implicaciones de la solución de la autonomía cultural. Krabbe examinaba la realización práctica de ese programa en Estonia, para juzgar si se revelaba como una solución "tan ideal como la presentan el Sr. Ammende y el Congreso". En primer lugar, destacaba que no todas las minorías nacionales europeas estaban de acuerdo sobre la fórmula de la autonomía cultural; y que ni siquiera dentro del CNE se había llegado a un debate profundo acerca de las posibles ventajas y desventajas del sistema, del que por lo general sólo se alababa su buen funcionamiento en Estonia, pues «os representantes de las minorías no buscan por sí mismos aclarar el problema exponiendo cómo ese sistema podría funcionar eventualmente en su caso y cuáles serían las dificultades a las que se enfrentaría, tanto por parte del Estado como de sus minorías». Según Krabbe, en Estonia sólo alemanes y judíos, por ser minotías «fuertes» intelectual y económicamente, y estar concentrados en áreas urbanas, aceptaron el sistema de autonomía cultural; mientras las minorías rusas y suecas no lo adoptaron, por preferir una autonomía administrativa, y no tener inclinación "por una organización susceptible de imponerles cargas fiscales demasiado pesadas para su situación económica». Del mismo modo, la minoría germana en Letonia, que no gozaba de la autonomía cultural, sí disfrutaba de cierta autonomía educativa, lo que era un contrapunto que no aparecía en los discursos de los teóricos del CNE, de los que afirmaba Krabbe, refiriéndose a Schiemann, su cariz "puramente teórico y filosófico». En consecuencia, la autonomía cultural no sería una garantía por sí misma de tratamiento liberal para las minorías, sino que sólo implicaba que «las minotías posee la autonomía cultural dentro de los marcos indicados por la ley de autonomía: si esos marcos son más o menos amplios, sobre ello no dice nada la expresión autonomía cultural». Por otro lado, la necesidad de que los miembros de una minoría se inscribiesen individualmente en un registro de nacionalidades no siempre resultaba tan sencillo, por la «falta de un sentimiento nacional muy pronunciado» o el miedo a «recibir impuestos más pesados que la población mayoritaria», el «malestar de ser considerados como una casta aparte», etc. Para ello recurría a la negativa de los alemanes de Hungría a inscribirse por temor a las represalias en un censo de nacionalidades, o recordaba el fracaso de la autonomía cultural en Carintia (Austria). En sus conclusiones, Krabbe apuntaba que, si bien la autonomía cuItural era una fórmula interesante para «disminuir las fricciones entre las mayorías y las minorías», estaba lejos de «detener sus conflictos fuera del restringido ámbito, aunque muy importante, de la educación». Por otro lado, su aplicación no podía recomendarse a todos los Estados, por razones políticas (suponía la creación de uunidades particulares dentro de un Estadon) y por la diversidad de condiciones de cada minoría nacional. En este sentido, Krabbe juzgaba de mayor interés el sistema de representación y autogobierno de los alemanes de Transilvania, de Letonia 
o de Checoslovaquia, basado en una participación en los Parlamentos estatales y consejos regionales ${ }^{81}$.

$\mathrm{El}$ acuerdo interno en cuestiones ideológicas dentro del $\mathrm{CNE}$ mostraba su fragilidad en varios puntos. Además de las diferencias entre tradiciones de pensamiento, doctrinales y estratégicas, que traducían la heterogeneidad de las nacionalidades representadas dentro de la organización, dentro de los círculos dirigentes de las minotías alemanas existían dos sectores ideológicos, uno de izquierda liberal y otro de derecha völkisch. Para el primero, la autonomía cultural era una solución suficiente; mientras que para el segundo, como recogía Boehm en 1935, algún tipo de vinculación política de las minorias germanas con el Estado alemán era ineludible y necesaria. Lo que venía también a significar que el segundo grupo no renunciaba a un futuro Estado nacional alemán que recuperase su dimensión imperial y que integrase a todos los individuos étnicamente germanos ${ }^{82}$. Examinemos ahora las teorías de los teóricos principales respectivos de ambos sectores: Paul Schiemann y Werner Hasselblatt.

\section{PAUL SCHIEMANN Y LA «DESNACIONAIIZACIÓN" DEL ESTADO}

El líder del grupo parlamentario alemán en el Parlamento letón y redactor jefe del periódico Rigascbe Rundschau Paul Schiemann fue el representante genuino del ala más liberal del CNE, así como su teórico más brillante. Su propia biografía expresa en buena medida el fracaso final de la aspiración de independencia del CNE ${ }^{83}$. Schiemann representaba aspiraciones idealistas que se situaban en el trasfondo de la actividad internacional pro-derechos de minorias en el período de entreguerras, así como las contradicciones de los optimistas políticos baltoalemanes que intentaron jugar una carta de política internacional desde su experiencia propia en Estonia y Letonia.

Paul Schiemann inspiró en buena medida los debates teóricos en el seno del $\mathrm{CNE}$, por lo que fue considerado el «ideólogo» de la organización ${ }^{84}$. Sin embargo, los objetivos finales de su ideología no fueron aceptados enteramente por el CNE, que acabó por considerarlos utópicos, como se reflejó en las discusiones que tuvieron lugar en las conferencias anuales de la organización

81 Informe de KraBBE, P., L'Autonomie culturelle comme solution du probleme des minorités, 18.11.1931 ([A]rchivo de la [S]ociedad de las [N]aciones, Ginebra, 4/32835/32835].

82 BOEliM, Volkstheorie, 34-35; id., "Die Reorganisation der Deutschtumsarbeit nach dem Ersten Weltkrieg», Ostdeutscbe Wissenschaft, V (1959), sin paginar.

83 VON RIMSCHIA, H., "Paul Schiemann als Minderheitenpolitiken», Viertejabrsheffe fär Zeitgeschichte, 4 (1956), 43-61; id., «Paul Schiemann», Jabrbuch für Geschicbte Osteuropas, 2 (1954), $475-78$.

84 Como señalaba Vilfan en el VII Congreso del CNE (1931). Vid. SB 1931, pág. 7. Sobre las teorías de Schiemann, vid. GARLEF, M, «Paul Schiemanns Minderheitentheorie als Beitrag zur Lösung der Minderheitenfrage», Zeitschriff für Ostforschung, 25 (1976), 632-59, asi como Dörr, M., «Paul Schiemanns Theorie von «anationalen Staabs. Ein Beitrag zur europäischen Nationalitätenbewegung zwischen den beiden Weltkriegenv, Geschicbte in Wissenschaft und Unterricht, 8 (1957), 407-20. 
hasta 1930. El significado de su actividad se debía en parte al hecho de que en la teoría de Schiemann es posible encontrar un sistema ideológico completo.

Las principales líneas del pensamiento de Schiemann pueden ser resumidas en tres puntos 85 : 1) Un firme liberalismo, basado en la preservación del desarrollo de los derechos humanos, reduciendo el poder del Estado al mínimo, que compatibilizaba con la creencia en la nacionalidad objetiva. Pero el criterio último de pertenencia del individuo a una nación radicaba siempre en su voluntad;

2) Una oposición coherente a cualquier forma de totalitarismo, por lo que rechazó la extensión del bolchevismo soviético al Báltico en 1918, y se situó en la oposición al nazismo tras 1933;

y 3) Una concepción europea del problema de las nacionalidades, resumible en su compromiso con el concepto de civilización ocidental.

Para Schiemann, el derecho de autodeterminación no constituía la única solución posible para el problema de las nacionalidades tras la Gran Guerra; por ello, rechazaba aquél por considerarlo basado en un concepto falso y equívoco del Estado: el Estado nacional. El acuerdo de principio de todos los nacionalismos europeos sobre la idea de Estado nacional como máximo garante de su cultura y derechos llevaba indefectiblemente al fracaso de toda pretensión de armonía entre mayorías y minorías nacionales. $Y$ en la medida en que las minorías, a su vez, aspirasen como reflejo a alcanzar una forma de autogobierno inspirado en el principio de autodeterminación, sólo llevaba al enfrentamiento étnico en Europa Centro-oriental, ya que con ello «deberían ser creados Estados dentro de los Estados, en la forma de autonomía personal o territorial, de modo que cada nacionalidad configuraría dentro del Estado nacional sus propios órganos de administración con funciones propias [...]. El pensamiento estatal en general, y en particular del Estado democrático, exigen una unidad de todos los ciudadanos en una tarea común...La aplicación de la autodeterminación en el interior de los Estados tiene como consecuencia no un entendimiento, sino una separación de las nacionalidades establecidas sobre un mismo territorio" ${ }^{86}$.

Por lo tanto, el rechazo de la idea del Estado nacional le llevaba a elaborar una nueva concepción del Estado, que se basará en la idea del Estado (anacionab), y que también era compartida en los años 20 y 30 por otros autores baltoalemanes como Kurt Stavenhagen, partidarios de la absoluta igualación de derechos de todas las nacionalidades dentro de un mismo Estado, aunque Schiemann se apartará de las concepciones neocorporativistas y antidemocráticas de Stavenhagen ${ }^{87}$. De

85 GarleFF, «Paul Schiemann», 646-47.

86 Schiemann, P., (Die Kulturautonomie als Lösung des Minderheitenproblems», Der Weg 2ur Freiheit (1926), paig. 122 (cit. por DöRR, «Paul Schiemanns Theorie», pág. 409). En términos muy semejantes, vid. el discurso de Schiemann en el II Congreso del CNE (1926), en SB 1926, 37-39.

87 Staventuagen, K, Das Wesen der Nation, Betlín: Vetlag von Robert Engelmann, 1934. Stavenhagen se caracterizaba por su rechazo de la democracia liberal y su elitismo social, que le llevaba a contraponer el concepto de "comunidad» (Gemeinschaff) al de umasas o conjunto del pueblo.

Hispania, LVIII/3, núm. 200 (1998) 1113-1151 
acuerdo con la concepción de Schiemann, las minotías nacionales deberían ser reconocidas legalmente como protagonistas activos y pasivos del Derecho Internacional en calidad de corporaciones [Körperschaften]. Lo que sería posible cuando el Estado hubiese renunciado a ciertas tareas y esferas de competencia, y cuando otras formas organizadas de vida social o comunidad fuesen autorizadas a existir como comunidades de iure, coexistiendo con el Estado. Esas comunidades formarían la Volksgemeinschaft, frente a la «asociación estatal» o Staatsverband ${ }^{88}$.

Como primer paso de su actividad teórica, Schiemann se concentró en la construcción de una teoría de los derechos de la «comunidad nacional». En un estadio posterior, y una vez que se alcanzase un acuerdo internacional legal y de principios sobre la satisfacción de las reivindicaciones de las nacionalidades, estarían dadas las condiciones para la traducción de esos derechos en un código de Derecho Internacional práctico: «Sólo cuando dentro de los Estados europeos se habrá creado un derecho positivo de las nacionalidades, ese vínculo jurídico estatal podrá ser garantizado por la comunidad internacional europea a través de un vínculo juridico internacionaly ${ }^{89}$.

La vía más efectiva para alcanzar ese objetivo era la separación nítida de los conceptos de Nación y Estado, una «desactivación del concepto del Estado nacionaly ${ }^{90}$. El responsable de todas las cuestiones legales y políticas relacionadas con el Estado no era la "nación étnica» [ethnisches Volk], sino la «nación política») [politiscbes Volk], con lo que la cuestión nacional se debía despolitizar. Con ello, no existiría oposición entre nacionalidad y ciudadanía. La esfera de actividades que debía corresponder al Estado comprendería las cuestiones políticas, sociales y económicas: todo lo relacionado con los intereses comunes del espacio vital en el que coexistían las nacionaliades ${ }^{91}$.

Schiemann define la comunidad nacional [Volksgemeinschaft] en base a la posesión común de un espíritu nacional, un Volksgeist. La nacionalidad se formaría de acuerdo con el principio personal, es decir, por la libre decisión de los individuos, pero cada uno de ellos se sentiría partícipe de una comunidad de pensamiento preexistente. Retomando las teorías de Renner y Bauer, Schiemann identificaba los elementos claves de la nacionalidad, además del $V o l k s g e i s t$, en la comunidad de cultura y de carácter, la historia compartida, tradiciones y orígenes remotos, que conjuntamente convertian a la comunidad nacional en una comunidad de destino ${ }^{22}$.

\footnotetext{
88 SchIEMANN, P., "Volksgemeinschaft und Staatsgemeinschaft», Nation und Stat, 1 (1927), 21-25.

89 Discurso de Schiemann, en SB 1926, pág. 37. Vid. también id., "Coudenhove und Rohann, Nation und Staat, $3(1929 / 30)$, 215-19.

${ }^{9}$ Discurso de Schiemann, en SB 1926, pág. 39.

1 Schiemann, Ein europäisches Problem, pág. 16; discurso de Schiemann en SB 1931, pág. 98.

92 SCHIEMANN, "Volksgemeinschafb, pág. 31. En ese aspecto, negaba que existiesen comunidades nacionales sin idioma propio.
} 
El mejor medio para llevar a efecto la separación efectiva entre Nación y Estado era la autonomía cultural en base al principio personal. Schiemann excluía cualquier forma de autonomía territorial, ya que en su opinión ello hacía incompatible desde el punto de vista teórico la existencia separada del Estado y de la nación. El Estado debía capacitar a las minorías nacionales para asumir la autonomía cultural, concediéndoles, en caso necesario, los medios financieros y legales precisos para ese cometido. Como ejemplo paralelo de realización de esa posibilidad, Schiemann recurría a la relación existente entre el Estado y las Iglesias, ya que el principio cuius regio eius religio establecido en Centroeuropa tras las guerras de religión de la Edad Moderna sería el origen de una forma diferente de comunidad (en este caso, de comunidad religiosa) que desde entonces fue capaz de convivir en armonía con el Estado, por ocuparse únicamente de cuestiones espirituales y culturales. De modo semejante, la comunidad nacional debía ser de carácter espiritual y cultural, y extenderse por encima de las fronteras de los Estados existentes. Europa, así, podría dividirse en dos clases diferentes de estructuras superpuestas, la «comunidad estatal, cuyos objetivos se derivan de la convivencia en un territorio estatal delimitado, y la comunidad nacional, que trabaja en el cuidado y desarrollo de la cultura nacional común» ${ }^{93}$. Esa solución sería aplicable a todos los Estados, tanto multinacionales como homogéneos étnicamente, y garantizaría la convivencia pacífica de las diversas naciones europeas, eliminando causas de conflicto internacional.

Para Śchiemann, los únicos medios para alejar a las nacionalidades de objetivos políticos y de la tentación de servir a los intereses revisionistas de su Mutterland serian:

1) el establecimiento de un sistema internacional basado en la armonía y conciliación entre todos los pueblos, que debería asumir la tarea de velar por el cumplimiento efectivo de los deberes de los Estados y de las naciones, lo que no significaba necesariamente una ampliación del sistema de protección de minorias de la SdN: Schiemann no fue más allá de proponer vagamente un Derecho Internacional mejorado y profundizado.

2) La condición real para evitar conflictos internacionales radicaba en el desarrollo de la despolitización de los fines y objetivos de la Volksgemeinscbaft ${ }^{94}$.

Una vez hubiese cambiado la situación interna de las nacionalidades en todos los Estados, los cambios en el orden internacional, según Schiemann, serían una suerte de consecuencia lógica. Pero, aunque preveía el peligro que podría implicar el apoyo a las minorías connacionales en otros Estados por parte del Estado «madre», el baltoalemán era menos coherente en este aspecto de su teoría, ya que consideraba que los Estados en los que una nacionalidad homogénea constituía claramente la mayoría podían convertirse en el «centro del sentimiento nacionaly de todos los miembros de esa nacionaldiad en

93 Discurso de Schiemann, en SB 1926, pág. 42.

94 SchiemanN, "Volksgemeinschafb), pág, 40; discurso de Schiemann, en SB 1926, pág. 41.

Hispanta, LVIII/3, núm, 200 (1998) 1113-1151 
Europa, e incluso estaría legitimado para intervenir en favor de sus connacionales si los derechos de la Volksgemeinstbaft eran amenazados por algún Estado en concreto ${ }^{25}$. El mismo Schiemann, en este aspecto, no podía eludir la contradicción que suponía que la actividad del CNE estuviese financiada en buena parte por el Gobierno alemán.

Schiemann consideraba que el problema de las nacionalidades revestía una dimensión europea y se ligaba a la preservación de la cultura cristiana occidental, lo que implícitamente suponía un rechazo de lo que para él representaba la Rusia bolchevique y «asiática». Una Europa unida sólo podría ser construida después de haber resuelto definitivamente las causas de conflicto étnico, por lo que criticaba los proyectos paneuropeos de Rohan, Coudenhove-Kalergi o Briand por no tener en cuenta ese aspecto. La común "conciencia europeas era señalada por Schiemann como un posible vínculo entre los Estados y las naw cionalidades, ya que la superposición de fronteras estatales y nacionales, y la separación entre Estado y Nación sería el mejor camino para la construcción de una patria común, Europa y la civilización europea, síntesis de las diferentes culturas de cada una de sus comunidades nacionales ${ }^{\%}$.

La fidelidad de Schiemann a la democracia parlamentaria y su rechazo al Estado nacional determinaron asimismo su oposición al ascenso de los fascismos europeos, y muy especialmente a la creciente influencia del pensamiento nacionalista antidemócrata y del nacionalsocialismo en Alemania durante los años 20 y 30. Ya en 1932, Schiemann definió al nazismo como una nueva ola de nacionalismo que manipulaba el concepto de Nación al servicio de los fines totalitarios de una «comunidad estatal de intereses» ${ }^{97}$. En el nazismo, Schiemann apreciaba igualmente, cuando ya se hallaba exiliado voluntariamente en Viena, la expresión de un nacionalismo egoísta que situaba los intereses de su Nación por encima de cualquier sentimiento de solidaridad y de conciencia del carácter europeo del problema de las nacionalidades, lo que para él constituía la única garantía de resolución de la cuestión de las minorías. Hitler habría traicionado el antiguo papel central de Alemania en la defensa de los derechos de minorías al imponer una concepción totalitaria de la Volksgemeinschaft a todas las minorias germanas, al haber apoyado al partido de Henlein en Checoslovaquia y al «envenenar la vida comunitaria de los alemanes del extranjero» ${ }^{98}$.

\section{EL. VOLK, ANTE TODO: WERNER HASSELBLATT}

El abogado y publicista Werner Hasselblatt era un líder destacado del Partido Baltoalemán de Estonia. Y, como tal, tuvo un importante papel en la consecución de la Ley de Autonomía Cultural de 1925. Hasselblatt se hallaba

\footnotetext{
95 Rigascher Rundschau, 13.12.1930, cit. por GARLEFF, «Nationalitätenpolitil», pág. 643.

96 Sclilimann, Ein europäisches Problem, pág. 42.

97 SchiemanN, P., «Die neue nationalistische Welle», Nation und Staat, 5 (1932), 799-811.

98 SCHIEMANN, Ein europässches Problem, 22-24.
} 
fuertemente vinculado desde comienzos de los años 20 a los circulos välkisch de la República de Weimar: como elios, profesaba una apreciación meramente instrumental de la democracia. El valor central sobre el que girará toda la actividad de Hasselblatt será su nacionalismo alemán de base organicista y antidemócrata, basado en una creencia en la vuelta a la organización corporativa, «orgánica» de la sociedad ${ }^{\text {? }}$.

A pesar de ello, dentro de su actividad en el CNE Hasselblatt era capaz de utilizar una terminología ambigua y semejante formalmente a la de Schiemann, además de compartir los objetivos estratégicos de la organización. Así, se sumaba a la defensa de la civilización occidental y presentaba la lucha de las minorías alemanas como una parte de la política de construcción europea, de la que la nación alemana sería piedra angular ${ }^{100}$. También empleará, en un sentido en principio análogo a Schiemann, los conceptos de comunidad nacional [Volksgemeinschaff y estatal [Staatsgemeinschaff], y no eludía interpretar la autonomía cultural estonia como una adaptación de las teorías de Renner y Bauer al contexto báltico. Si bien reconocía también en aquélla y en los principios rectores del CNE una pervivencia transformada de las tradiciones de «división orgánica» de la sociedad y «autogobierno corporativo», propias de los baltoalemanes, que a su vez enlazarian con el pensamiento corporativo elaborado por la derecha völkisch en Alemania ${ }^{101}$.

Durante los años 20, con todo, hubo entre Schiemann y Hasselblatt afinidades importantes, derivadas en parte en su común compromiso con el CNE. Ambos cuestionaban la compatibilidad entre Estado nacional y Nación en Europa Centro-oriental; aspiraban a transformar el Derecho Internacional de minorias en una suerte de norma jurídica interna que afectase y vinculase en su cumplimiento a los diferentes Estados plurinacionales; y propugnaban una

99 Sobre Hasselblatt, vid. GARLEFF, M., Deutschbaltische Politik qwischen den Weltkriegen. Die parlamentarische.Tätigkeit der deutschbaltiscben Parteien in Lettland und Estland, Bonn/Bad Godesberg: Wissenschaftliches Archiv, 1976, 70-75, y BOEHM, M.-H., «Werner Hasselblatt. Dem Andenken an diesen Kämpfer für das Recht der deutschen Minderheiten», Jabrbuch des baltischen Deutschitums, 1959, 72-75.

100 HASSELBLATT, W., «Notwendigkeit, Schwierigkeit und Ziel der übetstaatlichen deutschen Volksgemeinschaft), en Haushorer, K. y TrampLEx, K (eds.), Deutschlands Weg an der Zeitenvende, Munich: $\mathrm{H}$. Hugendubel Verlag, 146-55. Esa función especial de la nación alemana se justificaria por haberse apartado Rusia tanto cultural como políticamente de Europa, y porque Francia y Gran Bretaña estarían concentradas en sus imperios coloniales.

101 HASSEL BLATT, «Die Durchfihhrung der Kulturautonomie». Sobre el pensamiento corporativo en este periodo existe una abundante literatura. Vid. una exposición en BOEFM, Volkstheorie, 5657 , quien diferenciaba entre una opción «tradicionab», romántica y clásica, representada por Othmar Spann o W. Andreae, y otra corriente más modernizada y realista, representada por los teóricos de la revolución conservadora y discipulos de Moeller van den Bruck, entre ellos $\mathrm{H}$. Herrfahrdt y el mismo Boehm. Sobre la telación entre la derecha völkisch y los debates teóricos acerca de la cuestión de las minorías en este período, vid. una aptoximación én nuestro artículo «El nacionalismo radical alemán y la cuestión de las minorias nacionales durante la República de Weimar (1919-1933)», Studia Historica. Historia Contemporánea, 12 (1994), 259-85.

Hispania, LVIII/3, núm. 200 (1998) 1113-1151 
separación de funciones entre Estado y nacionalidad, perteneciendo a ésta última el dominio cultural a través de una administración propia. En sus propuestas de 1932 ante la Comisión de Minorías de la Union Internationale des Associations pour la Société des Nations, Hasselblatt aún se mostraba partidario de la solución de la autonomía cultural a partir de la libre decisión por parte del individuo para adscribirse a una nacionalidad determinada mediante su inscripción en un censo nacional, y presentaba como solución ideal la británica, que, en su opinión, constituía un ejemplo de «conexión de diferntes nacionalidades con la voluntad de pertenencia a una nación supranacionals ${ }^{102}$.

Sin embargo, las diferencias entre ambos líderes del CNE se irán agrandando con el paso de los años. Así, Hasselblatt se oponía al uso del término «minoría nacional», y prefería el de ugrupo étnico» [Volksgruppe], y en ese sentido consiguió en 1929 que la Unión de las Minorías Alemanas de Europa cambiase su nombre por el de Unión de los Grupos Étnicos Alemanes de Europa [Verband der deutschen Volksgruppen, VDV] ${ }^{103}$. Esa divergencia terminológica encerraba una consecuencia más relevante: una concepción diferente de lo que debía ser la relación entre el Estado y la nacionalidad, ya que Hasselblatt rechazó explícitamente desde comienzos de los años 30 las teotías de Estado anacional propuestas por Schiemann. Sin embargo, no construyó una teoría totalmente coherente: Hasselblatt se alineó crecientemente con la teoría völkisch de la "reunión de la nación en un Estado» y no descartó en lo sucesivo, especialmente tras 1933, la posibilidad de que un mismo Estado agrupase a todos los alemanes de Centroeuropa, pues el Estado era para él la realización más lograda de la nación. Durante los años 30 , Hasselblatt se referitá repetidamente al Estado de todos los alemanes como la "nación política» ${ }^{104}$. El objetivo lejano del movimiento nacionalitario europeo no debía consistir en la separación radical del Estado y la Nación, sino en el afianzamiento de los vínculos de identidad nacional de cada una de las nacionalidades de Europa Centro-oriental ${ }^{105}$. Aunque no llegaba a proponer el irredentismo como solución, tampoco elaboró una teoría propia acerca de la convivencia de diferentes nacionalidades dentro de un mismo Estado.

En razón de lo expuesto, la concepción que abrigaba Hasselblatt de una Europa de «comunidades nacionales» libres difería también notablemente de Schiemann. Para Hasselblatt, de modo paralelo al ideólogo nazi Alfred Rosen-

\footnotetext{
102 HASSELBLATT, W., Bericht zur Frage Zugebörigkeit eines Individuums zu einer nationalen Minorität, s.f. (1932) [ASN, P. 46/2].

103 Para Hasselblatt, el término uminoría nacional» encerraba una concepción minusvalorativa del contenido político y nacional de los grupos étnicos, además de ser sinorgánico, nivelador y surgido de una mentalidad de confrontación): vid. HASSELBLATT, W., "Die nationale Autonomie als Ziel der europäischen Nationalitätenpolitik», Deutschpolitiscbes Arbeitsamt, 32 (1930), 7-21 (especialmente, 14-16).

104 Hasselblatt, W., «Drei Wege», Nation und Staat, 6 (1931/32), pág. 143; id., «Dr. Kat! C. von Loesch zu seinem 60. Geburtstag», Nation und Staat', 14 (1940/41), pág. 70.

105 Vid. Grundmann, Deutscbiumspolitik, 345-46.
} 
berg, dentro de Europa existiría una suerte de «ámbito cultural nórdico-protestante», eje de una futura civilización europea cuyo centro sería Alemana y el Mar Báltico, y que habría de levantar barreras contra el «Este euroasiático» eslavo, pero que habria de preservar también su integridad contra el influjo de la «manera de ser occidental» 106. Aspecto en el que insistirá especialmente tras 1933, acercándose así a las ideas geopolíticas de la derecha völkisch y a la idea de "predestinación»» nacional del pueblo alemán.

Esos puntos de divergencia con el liberalismo nacionalitario de Schiemann posibilitaban que Hasselblatt encontrase un acomodo fácil en la nueva situación creada para las minorías germanas y para el CNE tras la subida de Hitler al poder en Berlín en enero de 1933. Hasselblatt se propondrá incluso presentar planes orientadores de la geopolítica nacionalitaria del III Reich, aunque sus memorándums no encontraron el eco esperado. Así, a partit de 1940 el baltoalemán propugnará desde las páginas de Nation und Staat una «reordenación nacionabs [Völkerneuordnung] de los pueblos de Eutopa Centro-oriental, en la que la nación alemana adquiriría el puesto de «poder director» que habrîa de asegurar los valores de la civilización occidental frente al bolchevismo y frente a las potencias de otras partes del planeta ${ }^{107}$. Sin embargo, y a diferencia de Rosenberg o Haushofer, para Hasselblatt la primacía de la nación alemana no implicaba la negación de la especificidad y derechos nacionales de otros pueblos, que habrian de ser transformadas en "personalidades nacionales productivas» dentro de una nueva kunidad de vidas ${ }^{108}$. En este sentido, Hasselblatt intentó repetidamente influir en Berlín para que la política exterior —y más tarde de ocupación- alemana en Europa oriental adoptase como líneas directoras de esa reordenación nacional el reconocimiento de la libertad de las diferentes nacionalidades de la Unión Soviética, aún sin excluir una jerarquización en función de los intereses del III Reich. De acuerdo con ello, dividía a las nacionalidades de Europa Septentrional y Oriental en sometidas, dominadas, favorables al Reich, amistosas y «estrechamente unidas», que a su vez podrían ser anexionadas al Imperio alemán en diferentes grados y formas de dependencia. Algunas zonas, según ese plan, habrian de ser uregermanizadas» a través de una política de asimilación amistosa y paulatina, como Hasselblatt defendía para los pueblos estonio y letón (rechazando, eso sí, la coerción individual: preferia una (ampregnación por etapası); mientras otras nacionalidades deberian ser amistosamente tratadas por los ocupantes alemanes, mediante una cooperación a su desarrollo económico y cultural que las transformase en «naciones amigas» ${ }^{109}$.

106 HasselBLATT, W., «Kräftespiel um die Ostseen, Jahrbuch des batischen Deutschtums, 1930, 94-97.

107 HASSELBLATT, W., (Zukunftsgestalgung aus Volksturm), Nation und Staat, 17 (1943/44), 176-85.

108 HasselbLATT, W., "Völkerpolitilo", pág. 225.

$109 V i d$ la serie de artículos de Hasselblatt «Die Völket des Ostens. Die volkspolitische Entwicklung im Ostraumy, en Nation und Stat desde el vol. 15 (1941/42), 300-312, hasta el 17 (1943/44), 67-70; igualmente, vid. MYLLYNEMI, S., Die Neuordnung der baltischen Länder 1941-1944. Zum nationalsoqialistiscben Inhalt der deutschen Besatzungspolitik, Helsinki: Univ. Helsinki, 1973, 5870, y GARLEFF, «Nationalitätenpolitik», 128-29.

Hippania, LVIII/3, núm. 200 (1998) 11t3-1151 
En este momento, las concepciones de Hasselblatt se hallaban ya muy lejos de las que habían inspirado el desarrollo y actividades del CNE, y sí correspondían, en la práctica, a las que abrigaban los teóricos del nacionalsocialismo, desde Rosenberg hasta el mismo Hitler. Pero sin el propósito de esclavización de naciones enteras y jerarquización racial incluido en los proyectos geoestratégicos nazis de reordenación europea, que la política de ocupación alemana puso en práctica durante la II Guerra Mundial con los resultados tristemente conocidos. 